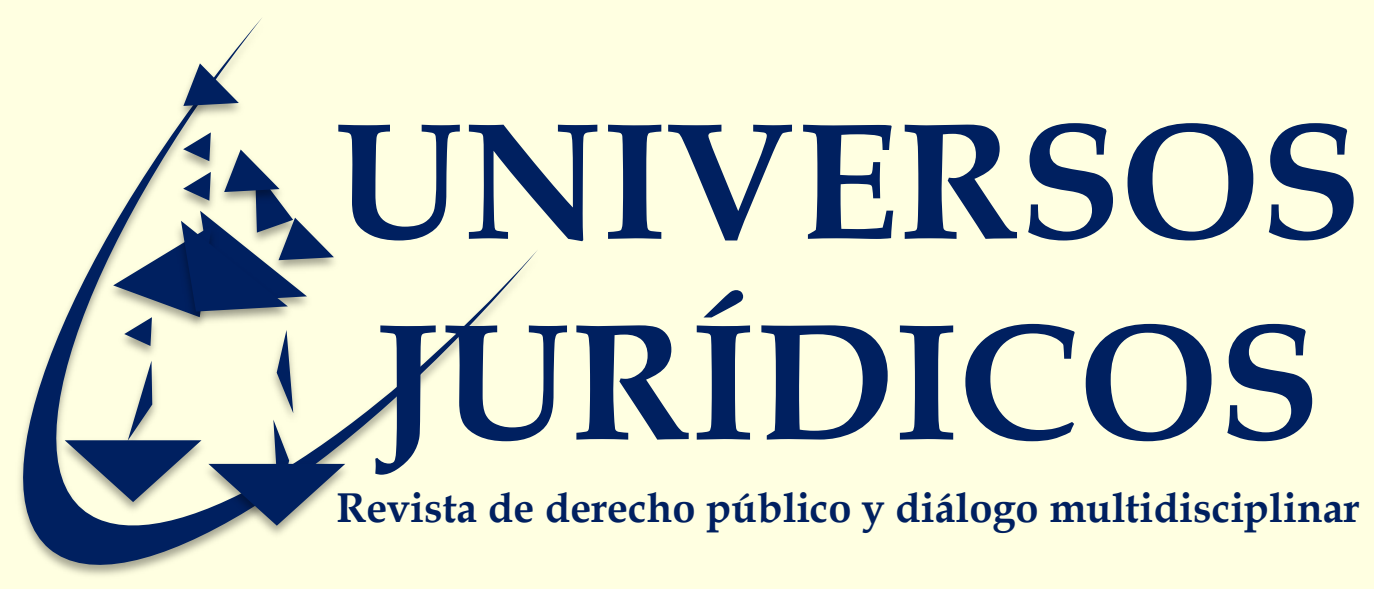

\title{
EL DESPLAZAMIENTO INTERNO FORZADO EN MÉXICO: INDÍGENAS, LAS VÍCTIMAS INVISIBLES
}

Paola Nayeli Huerta Rodríguez*

Licenciada en Derecho por la Universidad Veracruzana, Estudiante de la Maestría en Derechos Humanos y Juicio de Amparo en la Universidad de Xalapa.

UNIVERSOS JURÍDICOS. Revista de derecho público y diálogo multidisciplinar. Año 6, No. 11, diciembre 2018 - mayo 2019, ISSN 2007-9125 Cómo citar este artículo en formato APA Huerta, P. (2019). El Desplazamiento Interno Forzado en México: Indígenas, Las Víctimas Invisibles. Universos Jurídicos. 31-73.

Fecha de recepción: 27 de enero de 2019

Fecha de aceptación: 05 mayo de 2019 


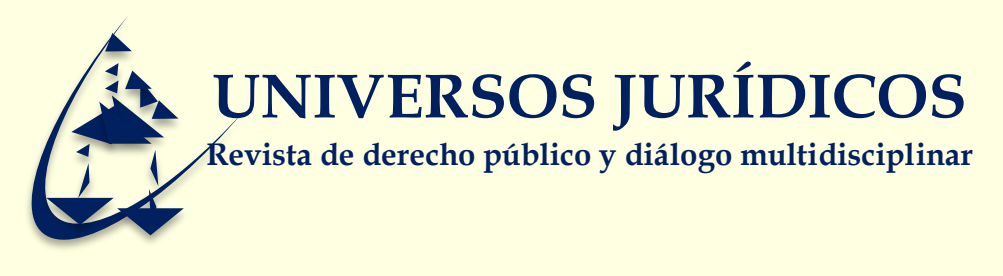

SUMARIO: I. Introducción, II. La libre determinación y protección de los pueblos originarios. III. Causas del desplazamiento interno forzado. IV. Los derechos humanos violentados frente al desplazamiento interno forzado. V. Ausencia de una legislación jurídico-reguladora a nivel federal sobre desplazamiento interno forzado. VI. Conclusiones. VII. Bibliografía.

\section{RESUMEN}

El presente tema se abordará desde la responsabilidad estatal de salvaguardar a este grupo en situación de vulnerabilidad, bajo los principios rectores de las víctimas de desplazamiento interno por violencia frente a la incapacidad del Estado Mexicano al prevenir, atender y reparar dicha situación a nivel federal, al tenor de los Derechos humanos.

\section{Palabras clave}

Desplazados, victimas, violencia. 


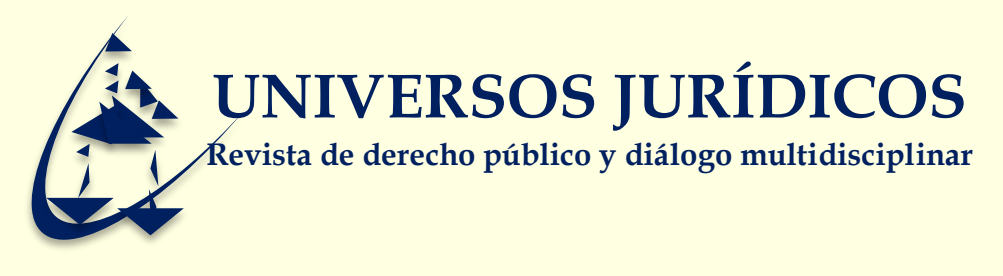

\section{Abstract}

The issue will be addressed from the state responsibility to safeguard this vulnerable group, under the guiding principles of victims of internal displacement by violence against the inability of the Mexican State to prevent, care for and repair this situation at the federal level in accordance with the Human Rights.

\section{Keywords}

Displaced, victims, violence.

\section{INTRODUCCIÓN}

Si bien es cierto la reforma constitucional en materia de derechos humanos del año 2011 ha sido la más progresiva y protectora para los derechos de las personas sin distinción de raza, sexo, religión, ideología política, origen étnico o nacionalidad, preferencias sexuales o cualquier otra que atente contra la dignidad humana, pero lo es únicamente en lo que al papel respecta, ya que la mayoría de las veces es una situación que en la realidad empírica de México no ocurre; prueba de ello es la discriminación a razón de su origen étnico que sufren en general las personas que 


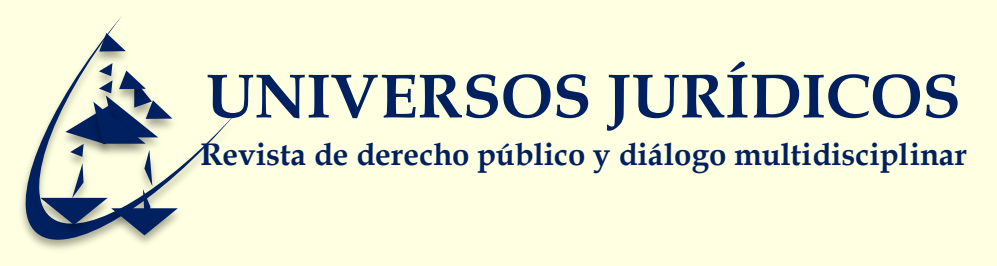

pertenecen a "pueblos originarios definiéndolos como aquellos que descienden de poblaciones que habitaban en el territorio actual del país al iniciarse la colonización y que conservan sus propias instituciones sociales, económicas, culturales y políticas, o parte de ellas (Constitución Política de los Estados Unidos Mexicanos, 1917, pág. 2)", clara demostración de ello es el tema abordado debido a que el legislador se ha negado implícitamente a proteger a las víctimas del desplazamiento interno forzado omitiendo además el resarcimiento del daño, manteniéndolos en un estado de indefensión violatorio de derechos humanos, ya que no solamente son inexistentes los recursos para hacer valer sus derechos, sino además, se demuestra poco interés sobre los mismos que no se cuenta con registros oficiales federales que documenten cuántas personas han sido desplazadas en el territorio nacional, siendo que la mayoría de ellos, -según la Comisión Mexicana de Defensa y Promoción de los Derechos Humanos A.C.- son indígenas. Históricamente, la causa de los desplazamientos internos forzados se ha generado debido a conflictos armados dentro de los estados como guerrillas en Colombia, dictaduras políticas en diversos países o Cárteles de la Droga en México, teniendo como causa la inhabilidad del Estado respectivo para implementar políticas públicas pertinentes que salvaguarden la vida y dignidad de sus subordinados, debido a que:

UNIVERSIDAD VERACRUZANA. Instituto de Investigaciones Jurídicas http:// universosjuridicos.uv.mx/index.php/univerjuridicos/index Xalapa, Veracruz, México 


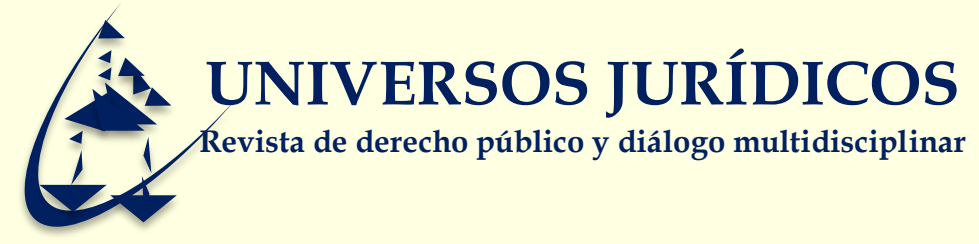

En México, como en el mundo el fenómeno del desplazamiento interno forzado no es un tema nuevo, ya que se remonta a la época de la intolerancia religiosa entre católicos y las minorías indígenas politeístas, los conflictos comunales, así como disputas por la tierra y recursos naturales (Rubio, 2014, pág. 111).

Sin embargo el caso más conocido de desplazamiento interno forzado en México es sin duda el relacionado con el movimiento del "Ejército Zapatista de Liberación Nacional -EZLN1- (Zolla, 2004, pág. 48)" y los reiterados enfrentamientos que ha tenido con el Ejercito Mexicano, mismo que tuvo como consecuencias desplazamiento interno forzado de comunidades indígenas y además en un caso extremo "la matanza de $\mathrm{Acteal}^{2}$,cometida por paramilitares en 1997 (Cruz, 2007, pág. 79)"; que ya a todas luces marcaba la ineficacia del Estado para lidiar con conflictos internos respetando los derechos humanos, que si bien no eran preponderantes en las practicas judiciales del México clásico sí debían ser observados y aplicados conforme al derecho internacional.

\footnotetext{
${ }^{1}$ Es una organización político-militar, formada mayoritariamente por indígena, cuya existencia se conoció públicamente el primero de enero de 1994 a raíz del levantamiento armado mediante el cual tomó la ciudad de San Cristóbal de Las Casas y las poblaciones de Las Margaritas, Altamirano, Chanal, Ocosingo, Oxchuc, Huixtán, Chalam, Simojovel y San Andrés Larráinzar, La Declaración de la Selva Lacandona fue el primer documento público del EZLN, la cual exponía las demandas del grupo que consistían en "trabajo, tierra, techo, alimentación, salud, educación, independencia, libertad, democracia, justicia y paz".

${ }^{2}$ Matanza de 26 civiles indefensos en diciembre de 1997, perpetrada por un grupo de personas con armas de alto poder, es sin duda el incidente más grave y dramático que se haya producido en el marco de conflicto de Chiapas. Fue consecuencia de la política oficial seguida para castigar y desarticular a los indígenas de San Pedro Chenalhó que adoptaron el camino de la resistencia y la construcción de un gobierno propio (Cuevas, 2007), fecha de consulta 24 de enero de 2019, disponible en https://www.jornada.com.mx/2007/12/22/index.php?section=politica\&article=007n1pol.
}

UNIVERSIDAD VERACRUZANA.

Instituto de Investigaciones Jurídicas

http:// universosjuridicos.uv.mx/index.php/univerjuridicos/index

Xalapa, Veracruz, México 


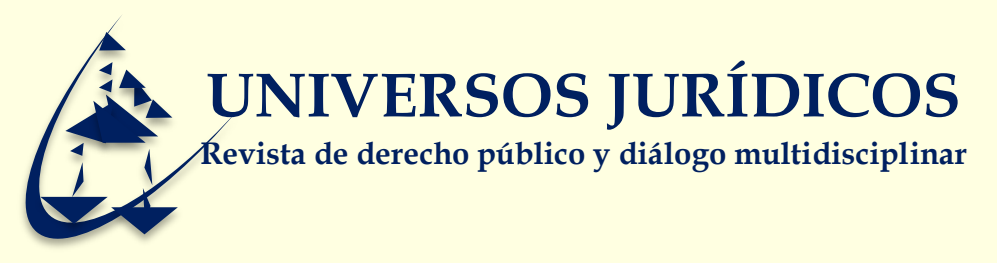

Más recientemente estos conflictos armados se han visto emerger nuevamente y con más fuerza a raíz de la llegada de Felipe Calderón Hinojosa al cargo de Presidente de la República, con su estrategia de seguridad que buscaba mermar la violencia que experimentaba el país durante su sexenio -y que hasta la actualidad sigue imperando- declarando una "guerra" contra el narcotráfico y sus cárteles, que aparte de dejar miles de muertos y heridos, las victimas no contabilizadas son los desplazados internos que se vieron forzados a abandonar sus lugares de residencia debido a la inseguridad causada por conflictos armados que sin piedad se llevaban a cabo en pleno centro de las ciudades y pueblos; no sin dejar de lado que al verse reducidos y afectados los sembradíos de droga, así como los lugares denominados como casas de seguridad los delincuentes buscaron refugiarse en comunidades alejadas como ejidos, sierras y etnias donde le fuera difícil al Ejercito Mexicano ingresar, lo que consecuentemente dejó en estado de indefensión a sus habitantes debido a que eran asesinados para quedarse con sus tierras y sembrarlas con droga, por su parte los sobrevivientes eran capturados y obligados a trabajar para el crimen organizado, en el mejor de los casos huían con sus familias a otros poblados para no ser alcanzados por la delincuencia, siendo casi imposible el regreso a sus residencias. 


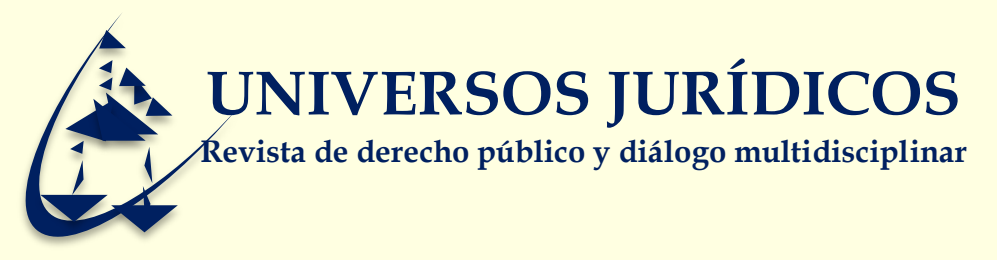

\section{La libre determinación y protección de los pueblos originarios}

La movilidad de comunidades indígenas es ocasionada por diversa razones entre las cuales se encuentran "la falta de apoyo a la producción agropecuaria, la caída del mercado cafetalero, el crecimiento urbano y la expulsión de familias indígenas por motivos religiosos, que ya aparece como problema grave en México a partir de 1980 (Cruz, 2007, págs. 71-72)”, agregando actualmente la violencia.

Todo lo anterior en perjuicio y contraviniendo el artículo $2^{\circ}$ de la Constitución Política de los Estados Unidos Mexicanos, el cual indica que nuestra nación está compuesta multiculturalmente, integrada por pueblos originarios que cuentan con una libre determinación y autonomía dentro de sus territorios, reconociéndoles el derecho a "determinar sus formas de convivencia y organización social, económica, política y cultural", así mismo la Constitución en el citado artículo $2^{\circ}$ reconoce y garantiza que los pueblos y comunidades indígenas tienen derecho a:

[...] V. Conservar y mejorar el hábitat y preservar la integridad de sus tierras en los términos establecidos en esta Constitución. VI. Acceder, con respeto a las formas y modalidades de propiedad y tenencia de la tierra establecidas en esta Constitución y a las leyes de la materia, así como a los derechos adquiridos por terceros o por integrantes de la comunidad, al uso y disfrute preferente de los recursos naturales de los lugares que habitan y ocupan las comunidades [...].

UNIVERSIDAD VERACRUZANA.

Instituto de Investigaciones Jurídicas

http:// universosjuridicos.uv.mx/index.php/univerjuridicos/index

Xalapa, Veracruz, México 


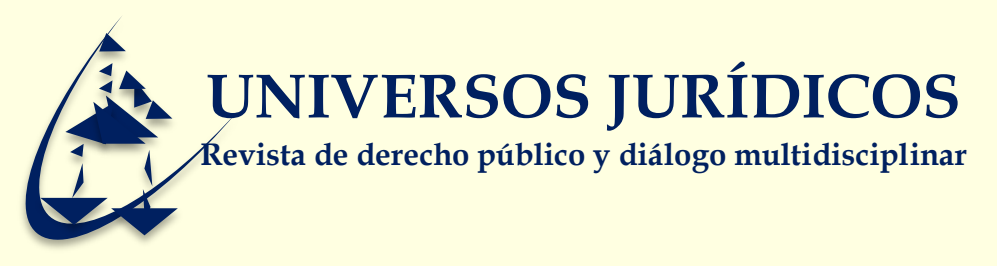

Con ello la Carta Magna garantiza los derechos de estos grupos en situación de vulnerabilidad, así como la protección a sus medios de subsistencia donde se desarrollan mediante actividades productivas primarias, pero en este sentido las tierras de las comunidades donde se desenvuelven no constituyen únicamente un patrimonio, sino, una forma de vida, que significa una cosmovisión ancestral mediante la cual desarrollaron apego con la misma, así como con sus tradiciones culturales, es decir:

Los miembros de las comunidades indígenas corresponde a una forma de vida particular de ser, ver y actuar en el mundo, constituido a partir de su estrecha relación con sus tierras tradicionales y recursos naturales, no sólo por ser estos su principal medio de subsistencia, sino además porque constituyen un elemento integrante de su cosmovisión, religiosidad y, por ende, de su identidad cultural (Masacre de Río Negro Vs. Guatemala, 2012, pág. 177).

Condición establecida además en el Pacto Internacional de Derechos Económicos, Sociales y Culturales en su artículo $1^{\circ}$ inciso 2 que a la letra estipula que "en ningún caso podrá privarse a un pueblo de sus propios medios de subsistencia". Es por ello que cuando los conflictos armados llegan a estas congregaciones, no solo afectan el patrimonio de las comunidades, sino, sus estructuras culturales, colocándolos en una situación de especial vulnerabilidad debido ya que dentro del grupo de desplazados internos se encuentran, mujeres, niños, adultos mayores, etc., que por su sola condición son considerados como grupos merecedores de una 


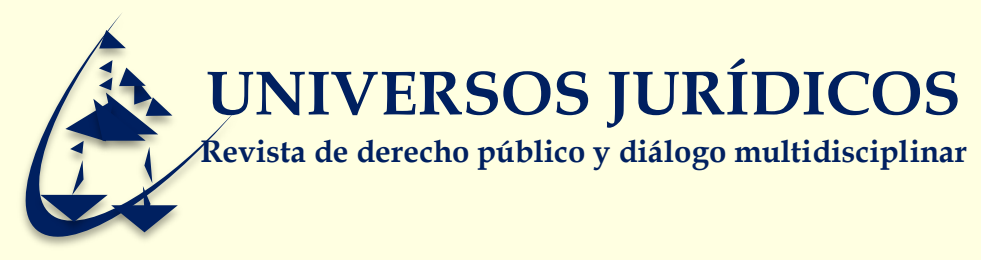

especial protección por parte del Estado, tal y como lo mostró la Comisión Mexicana de Defensa y Promoción de los Derechos Humanos A.C., en su informe publicado en el año 2017 denominado "Episodios de Desplazamiento Interno Forzado Masivo en México, del cual se pueden destacar el gráfico 1 que permiten vislumbrar la magnitud del problema del desplazamiento interno forzado.

\section{Gráfico 1.- Tipo de población internamente desplazada por violencia}

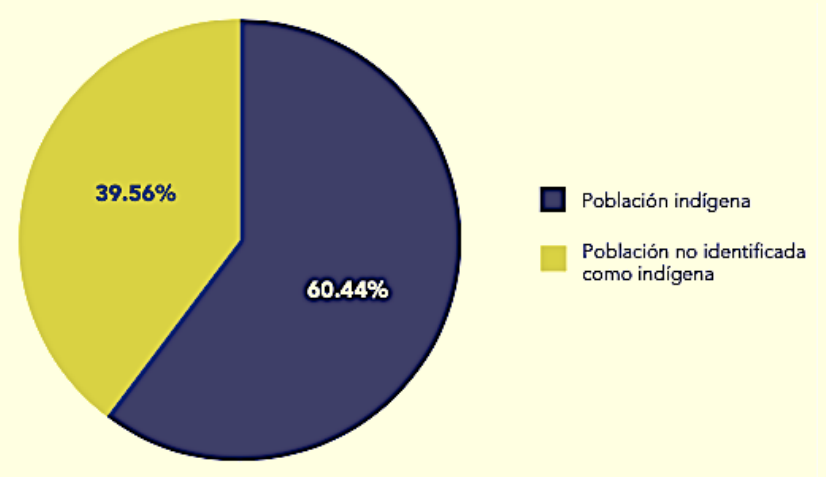

(Comisión Mexicana de Defensa y Promoción de los Derchos Humanos, 2018, pág. 21)

Sólo basta observar la gráfica para constatar que más de la mitad de la población que se ha visto afectada por este problema pertenece a poblaciones indígenas identificados como "nahuas, tzotziles, mixes, rarámuris (o tarahumaras), purépechas y tepehuanes (u ódami). Los grupos más afectados fueron los tzotziles 


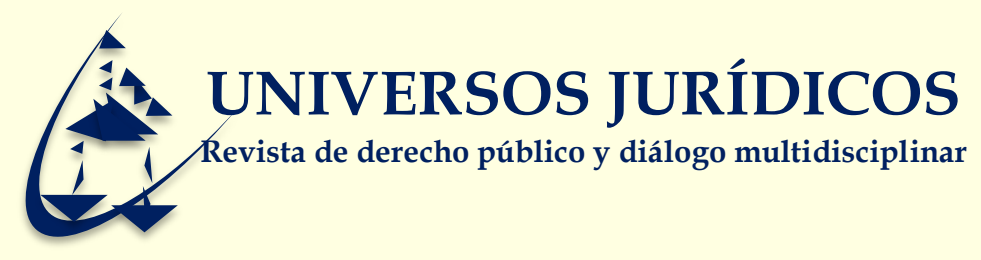

(5,890 personas) y los nahuas (3,640 personas) (Comisión Mexicana de Defensa y Promoción de los Derchos Humanos, 2018, pág. 20)”.

En éste sentido, "es indispensable que los Estados adopten medidas específicas de protección considerando las particularidades propias de los pueblos indígenas, así como su derecho consuetudinario, valores, usos y costumbres para prevenir y revertir los efectos de dicha situación (Masacre de Río Negro Vs. Guatemala, 2012, pág. 177)", tales medidas necesarias no obran únicamente en legislación internacional, también se encuentran estipuladas en la Constitución Federal como medidas para contrarrestar la pobreza y marginación de las comunidades indígenas, que al mismo tiempo se traducen en obligaciones del Estado para proteger a todos los ciudadanos de la entidad como primer garante de los Derechos Humanos (en adelante DDHH), dentro de estas obligaciones estipuladas en el artículo $2^{\circ}$ inciso B fracción VIII Constitucional podemos encontrar:

\footnotetext{
Establecer políticas sociales para proteger a los migrantes de los pueblos indígenas, tanto en el territorio nacional como en el extranjero, mediante acciones para garantizar los derechos laborales de los jornaleros agrícolas; mejorar las condiciones de salud de las mujeres; apoyar con programas especiales de educación y nutrición a niños y jóvenes de familias migrantes; velar por el respeto de sus derechos humanos y promover la difusión de sus culturas.
}

UNIVERSIDAD VERACRUZANA.

Instituto de Investigaciones Jurídicas

http://universosjuridicos.uv.mx/index.php/univerjuridicos/index

Xalapa, Veracruz, México 


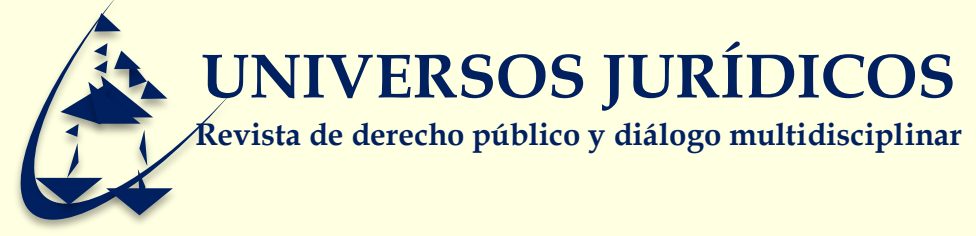

Desafortunadamente, los estudios de estos casos se han tratado de forma casuística por parte del Estado, ya que la misma autoridad es omisa al momento de regular y reparar el daño causado a estas comunidades, siendo que el estudio más reciente del año 2018 fue llevado acabo por La Comisión Mexicana de Defensa y Promoción de los Derechos Humanos A.C., evidenciando la apatía de la entidad federativa para atender los caso, argumentando que no se cuenta con recursos materiales para llevar a cabo ninguna de las acciones a las que encuentran obligados como prevenir y reparar el daño causado por su acción u omisión al momento de garantizar los derechos de las personas internamente desplazadas; en éste sentido podría considerarse como un delito continuado, ya que si bien no es equiparable a la desaparición forzada, si constituye un daño que se agrava continuamente cada día que pasan los desplazados fuera de sus comunidades, y el cual no se ve reparado hasta que las personas forzadas a desplazarse puedan regresar a sus comunidades o el Estado les ayude a construir otra comunidad si el daño a la anterior es irreparable material o inmaterialmente debido a que "perdieron los vínculos comunitarios y afectivos de sus raíces, además de los bienes materiales, lo que derivó en cambios forzados en la estructura social, lo cual implicó rupturas, pérdidas, dolor, y mucho sufrimiento (Masacre de El Mezote y Lugares Aledaños Vs. El Salvador, 2012, pág. 194)", en este sentido para poder reparar el 


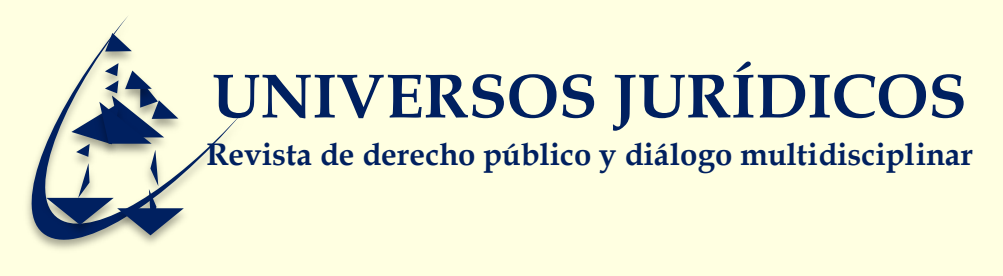

daño primero se deben identificar a las víctimas, situación que se ha vuelto casi inconcebible debido a que no se cuenta con los registros necesarios de las

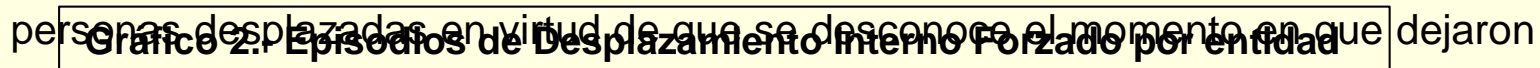
federativa

la comunidad y a qué lugar se dirigieron, también se ignoran la forma en que abandonaron la misma, si fue en grupos, por familias o individualmente. Aunado a la discriminación que siempre han sufrido las personas pertenecientes a etnias originarias "dicha condición es reproducida por prejuicios culturales que dificultan la integración de los desplazados a la sociedad y pueden llevar a la impunidad de las violaciones de derechos humanos cometidas en su contra (Masacre de Mapiripán Vs. Colombia, 2005, pág. 177)”. Por otra parte, a nivel estatal, únicamente dos Estados cuentan con legislaciones que pretenden prevenir, sancionar y resarcir los daños, las cuales son Chiapas y Guerrero, debido al gran éxodo de desplazamiento interno forzado que viven cada año a razón de las precarias situaciones económicas que se viven en esos estados mostrado en el Gráfico .

UNIVERSIDAD VERACRUZANA. Instituto de Investigaciones Jurídicas http:// universosjuridicos.uv.mx/index.php/univerjuridicos/index Xalapa, Veracruz, México 

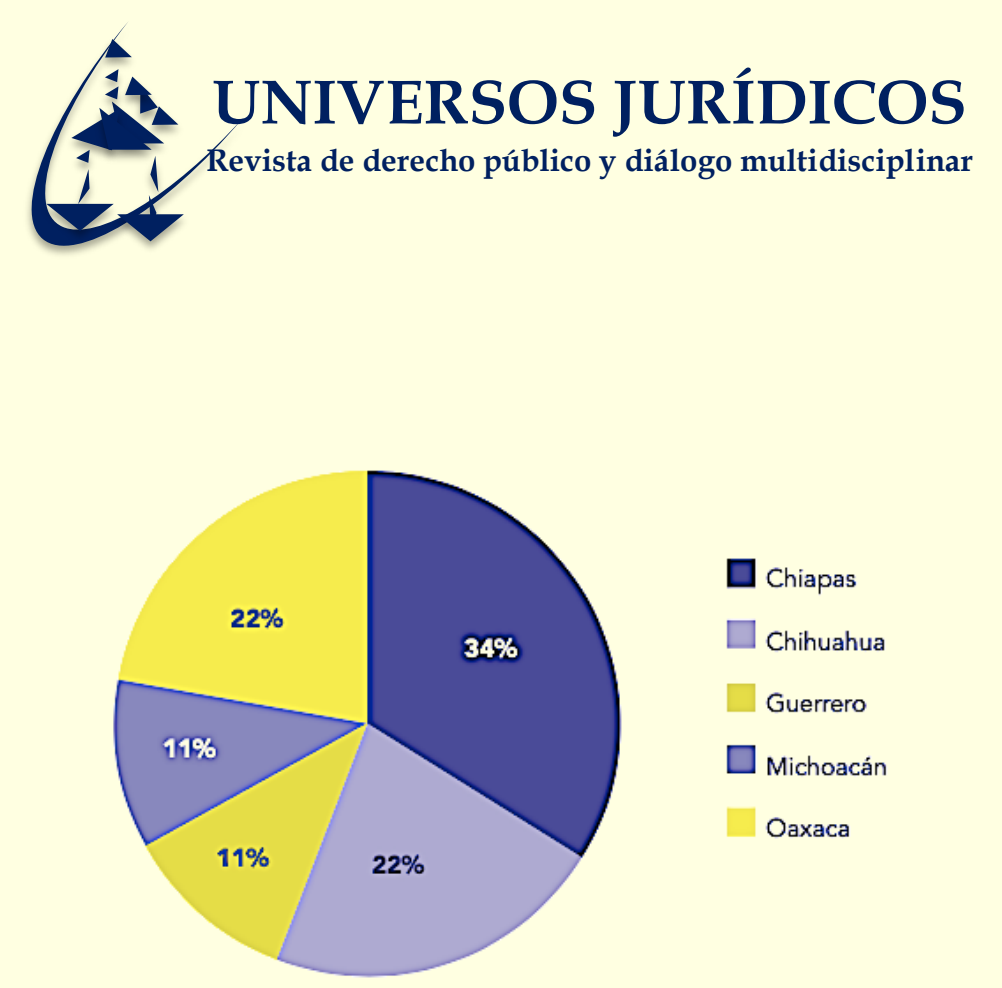

(Comisión Mexicana de Defensa y Promoción de los Derchos Humanos, 2018, pág. 19)

Por su parte, México incurre en responsabilidad internacional al:

No reconocer de lleno la existencia de dicho fenómeno, al menos de manera abierta, no ha formulado políticas públicas que permitan el resarcimiento del daño, por un lado, y, por otro y más urgente, el retorno a sus comunidades para recuperar su patrimonio e insertarse nuevamente al territorio indígena al que pertenecen, y de esa forma restablecer su relación con la tierra, que es fundamental en la cultura indígena (Mercado, 2019, pág. 187).

Demostrando de esta manera que a pesar de la reforma en materia de derechos humanos continúa siendo un país clasista y discriminatorio, cuyo principal fin no es salvaguardar los derechos humanos de sus gobernados.

UNIVERSIDAD VERACRUZANA. Instituto de Investigaciones Jurídicas http://universosjuridicos.uv.mx/index.php/univerjuridicos/index Xalapa, Veracruz, México 


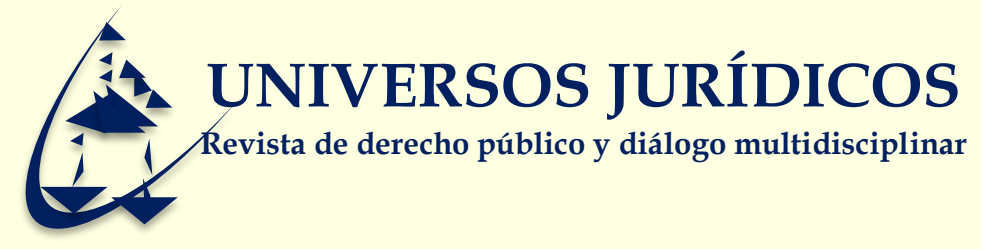

\section{Causas del desplazamiento interno forzado}

Antes de abordar las causas del desplazamiento interno forzado en México, se debe conceptualizar adecuadamente para que no sea confundido con el derecho de las personas refugiadas, es por ello que los Principios Rectores de los Desplazamientos Internos de las Naciones Unidas los definen como:

Las personas o grupos de personas que se han visto forzadas $u$ obligadas a escapar o huir de su hogar o de su lugar de residencia habitual, en particular como resultado o para evitar los efectos de un conflicto armado, de situaciones de violencia generalizada, de violaciones de los derechos humanos [...], y que no han cruzado una frontera estatal internacionalmente reconocida.

Por otro lado, las personas refugiadas, de acuerdo al artículo $1^{0}$ de la Convención de los Estatutos de los Refugiados adoptada en Ginebra, se desplazan principalmente debido a:

Fundados temores de ser perseguido por motivos de raza, religión, nacionalidad, pertenencia a un determinado grupo social u opiniones políticas, se encuentre fuera del país de su nacionalidad y no pueda o, a causa de dichos temores, no quiera acogerse a la protección de su país; o que careciendo de nacionalidad y hallándose, a consecuencia de tales acontecimientos fuera del país donde antes tuviera su residencia habitual, no pueda o, a causa de dichos temores no quiera regresar a él.

Situación que ha mermado cada vez más los grupos vulnerables de la entidad mexicana, principalmente en los estados de Oaxaca, Chiapas, Guerrero, Michoacán y más recientemente Sinaloa debido al crimen organizado que impera en el llamado "triángulo dorado" de la droga y en general por violencia en todas sus

UNIVERSIDAD VERACRUZANA.

Instituto de Investigaciones Jurídicas

http://universosjuridicos.uv.mx/index.php/univerjuridicos/index

Xalapa, Veracruz, México 


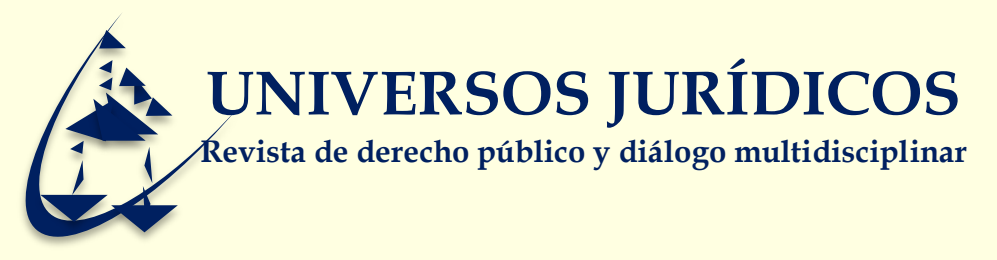

formas, debido a la ineficacia del Estado para salvaguardar la vida e integridad de sus pobladores, ya que "estos episodios en Guerrero, Sinaloa y Michoacán. Del total de 11,491 personas internamente desplazadas en $2018,6,156(53.6 \%)$ se desplazaron debido a la violencia generada por grupos armados organizados (Comisión Mexicana de Defensa y Promoción de los Derchos Humanos, 2018, pág. 20)", por conflictos territoriales en el caso de ejidatarios y campesinos, por proyectos de desarrollo que merman el hábitat de las comunidades como las empresas de minería, etc., lo que a su vez genera una re victimización de las personas forzadas a desplazarse debido a que durante su trayecto sufren una "crisis de seguridad, dado que los grupos de desplazados internos se convierten en un nuevo foco o recurso de reclutamiento para los propios grupos paramilitares, de narcotráfico (Masacre de Mapiripán Vs. Colombia, 2005, pág. 175)”, víctimas de extorsiones, de robos a viviendas, a sus cultivos y animales, así como amenazas e intimidación, es por ello que su particular situación puede ser entendida como una "condición de facto de desprotección (Masacre de Río Negro Vs. Guatemala, 2012, pág. 174)", problema que se representa en el Gráfico 3. 


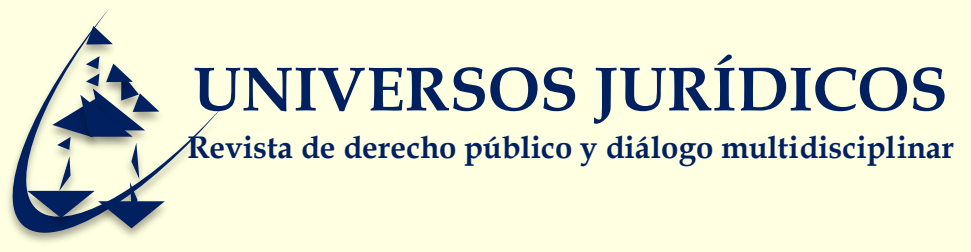

\section{Gráfico 3: Número de personas internamente deslazadas por la fuerza de acuerdo a las causas.}

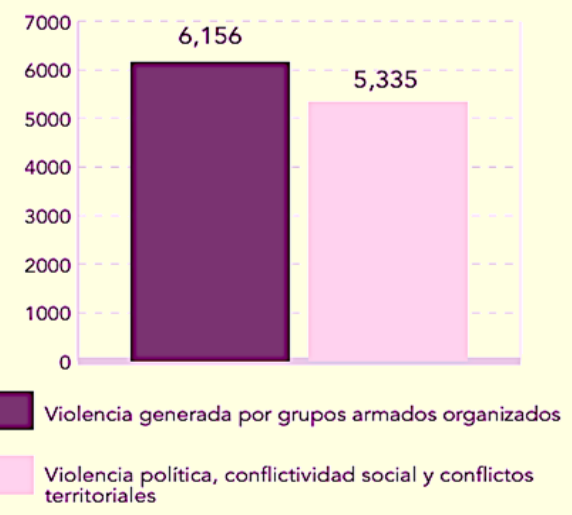

(Comisión Mexicana de
Defensa y Promoción de los
Derchos Humanos, 2018, pág.
20).

Así mismo el desplazamiento interno forzado puede ser de dos tipos, reactivo y preventivo:

El primero se refiere a los daños que ha causado un conflicto de cualquier tipo y el cual se ha desarrollado en situaciones de violencia; el segundo, es propiciado para prevenir o evitar los efectos violentos de un conflicto social, político, religioso, armado, etc. Generalmente se da a causa de amenazas, alertas, insultos, ofensas, etc. partiendo de un suceso o conflicto violento previamente acontecido y del cual la población que se desplazada tiene conocimiento (Aquino, 2008, pág. 37).

Ahora bien, las regulaciones sobre desplazamiento contenidas en el Protocolo II de Los Convenios de Ginebra de 1949; específicamente, el artículo 17:

Prohíbe ordenar el desplazamiento de la población civil por razones relacionadas con el conflicto, a no ser que así lo exijan la seguridad de las personas civiles o razones militares imperiosas y, en este último caso, se deberán adoptar todas las medidas posibles para que la población civil sea acogida en condiciones

UNIVERSIDAD VERACRUZANA.

Instituto de Investigaciones Jurídicas

http://universosjuridicos.uv.mx/index.php/univerjuridicos/index

Xalapa, Veracruz, México 


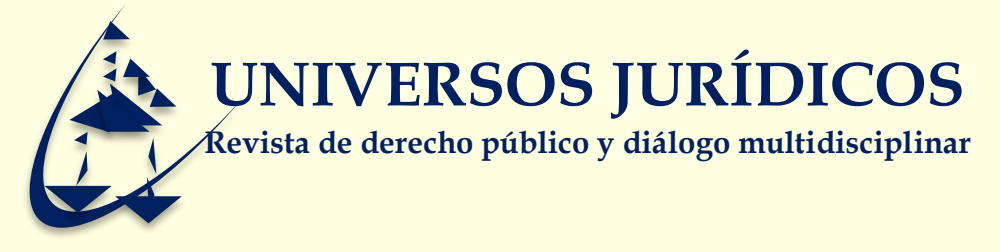

satisfactorias de alojamiento, salubridad, higiene, seguridad y alimentación (Masacre de Ituango Vs. Colombia, 2006, pág. 209).

Tomando en cuenta que las circunstancias de dicho desplazamiento ocurren bajo un ambiente de inseguridad y enfrentamientos militares se puede alegar la aplicación del artículo 17 anterior, sin embargo ello no libera al Estado de la responsabilidad de proteger y garantizar los DDHH de los grupos en situación de vulnerabilidad, condición que se encuentra por demás sobre pasada debido a los altos índices de marginación y pobreza que se pueden apreciar a simple vista en cualquier comunidad étnica del país, es por ello que si bien la raíz general de problema que nos ataña es la inseguridad causada por el narcotráfico que desemboca en enfrentamientos armados causando miedo en la sociedad, el trasfondo va más allá, la verdadera razón de los problemas sociales es la carencia, miseria, segregación y rechazo que sufre el sector de la sociedad que se encuentra más desprotegido y menos favorecido por los recursos estatales, a causa de la impunidad y la corrupción del Estado Mexicano, mismos que en un ámbito general conllevan a la sociedad a delinquir debido a que no cuentan con los recursos necesarios para una vida digna, como educación, salud, vivienda, etc., siendo ésta la razón por la cual la delincuencia organizada dentro del país es casi imposible de 


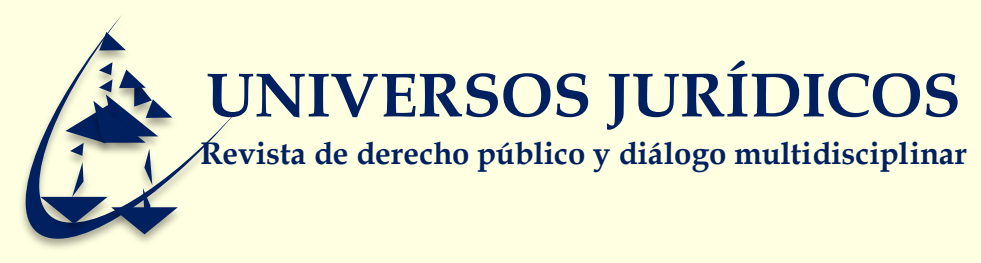

erradicar, y mientras estas condiciones no cambien, la violencia en el país no cesará. Aunado a lo anterior:

\begin{abstract}
Dentro de los efectos nocivos que provoca el desplazamiento forzado interno, se han destacado la pérdida de la tierra y de la vivienda, la marginación, graves repercusiones psicológicas, el desempleo, el empobrecimiento y el deterioro de las condiciones de vida, el incremento de las enfermedades y de la mortalidad, la pérdida del acceso a la propiedad entre comuneros, la inseguridad alimentaria y la desarticulación social (Masacre de Ituango Vs. Colombia, 2006, pág. 213).
\end{abstract}

Condiciones que lastimosamente no son nuevas para las personas que sobreviven en comunidades alejadas de la periferia urbana, la realidad es que si bien el desplazamiento interno forzado los obliga a abandonar sus hogares y medios de dificultosa subsistencia, las demás consecuencias a las que están sujetos eran condiciones que ya vivían diariamente dentro de sus comunidades.

En éste sentido, el Estado no ha cumplido sus obligaciones de garantizar una vida digna mucho antes que los conflictos armados arribaran a éstas poblaciones, es por ello que ahora con la situación de grupos armados entrando a las mismas y obligando a los pobladores a abandonarlas resulta irrisible pensar que el Estado podrá dar una solución más amplia e integral cuando en un debido momento menos complicado, no lo hizo; ámbito que nada tiene que ver con militancias políticas y partidos hegemónicos, si no, más bien es una cuestión de sociedad, ya que el Estado como ente regulador de la moral pública está determinado efectivamente

UNIVERSIDAD VERACRUZANA.

Instituto de Investigaciones Jurídicas

http://universosjuridicos.uv.mx/index.php/univerjuridicos/index

Xalapa, Veracruz, México 


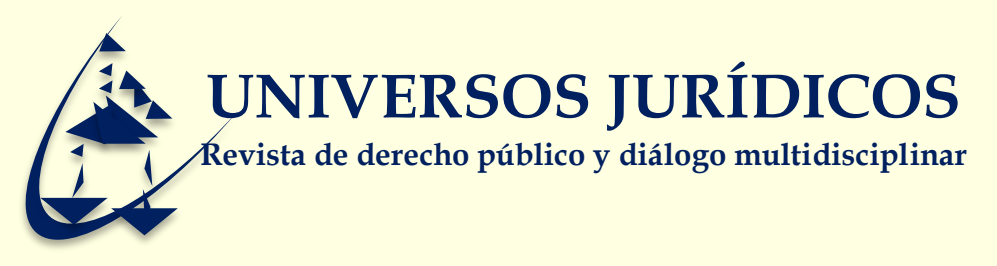

por ello mismo, la moral de la sociedad, puesto que si la sociedad mexicana no deja de segregar y discriminar a los pueblos originarios en razón de su étnica y condición social, negándoles las oportunidades para desarrollarse y tener un nivel de vida adecuado, colocándolos en situaciones de vulnerabilidad por su procedencia rural, se convierte en una cuestión que a la par de la delincuencia no tendrá fin. Sin embargo las comunidades indígenas por si solas y dentro de su propio ambiente a pesar de las precarias condiciones en que viven, son fuertes y capaces de desarrollarse, además de:

\begin{abstract}
Abastecerse en parte de los bienes necesarios para su subsistencia de haber estado en posesión de sus tierras tradicionales. El desplazamiento de los miembros de la Comunidad de estas tierras ha ocasionado que tengan especiales y graves dificultades para obtener alimento, principalmente porque la zona que comprende su asentamiento temporal no cuenta con las condiciones adecuadas para el cultivo ni para la práctica de sus actividades tradicionales de subsistencia, tales como caza, pesca y recolección (Comunidad Indígena Yakye Axa Vs. Paraguay, 2005, pág. 164).
\end{abstract}

En cuanto a la las formas de reparación de las cuales deben ser beneficiadas las personas forzadas a desplazarse internamente por excelencia se encuentra la reivindicación de sus tierras, así como el necesario establecimiento de "mecanismos para registrar y prestar atención de emergencia a la población desplazada (Masacre de Ituango Vs. Colombia, 2006, pág. 214)" por que actualmente al no contar con uno, resulta casi imposible saber cuántas personas han sido afectadas y con ello la magnitud del problema y solución que se necesita,

UNIVERSIDAD VERACRUZANA.

Instituto de Investigaciones Jurídicas

http://universosjuridicos.uv.mx/index.php/univerjuridicos/index

Xalapa, Veracruz, México 


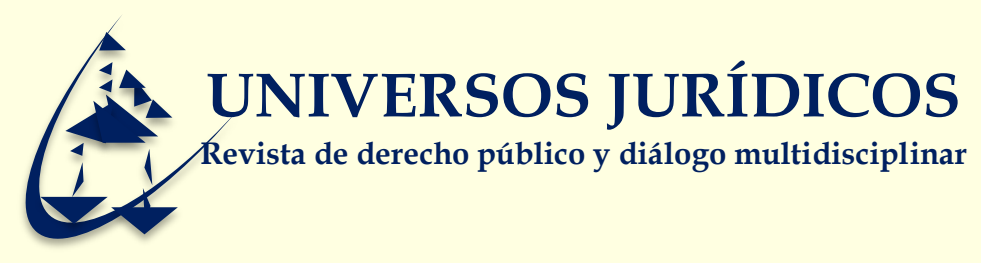

salvo por asociaciones civiles que se han dedicado a cuantificar dicha problemática aun sin contar con los recursos necesarios para dicha actividad; también se debe prestar "especial atención a las necesidades y a los derechos de los niños, en consideración a su condición particular de vulnerabilidad (Familia Barrios Vs. Venezuela, 2011, pág. 168)", así como la implementación de programas estatales y federales para prevenir, prestar atención de manera urgente y en su caso reparar el daño causado.

Por consiguiente, en materia de resarcimiento, regreso y reintegración de los desplazados internos, el Estado tiene la obligación de acuerdo con Los principios rectores de los Desplazamientos Internos de las Naciones Unidad de:

Principio 28.1. Las autoridades competentes tienen la obligación y responsabilidad primarias de establecer las condiciones y proporcionar los medios que permitan el regreso voluntario, seguro y digno de los desplazados internos a su hogar o su lugar de residencia habitual, o su reasentamiento voluntario en otra parte del país.

Principio 28.2. Se harán esfuerzos especiales por asegurar la plena participación de los desplazados internos en la planificación y gestión de su regreso o de su reasentamiento y reintegración.

Principio 29.2. Las autoridades competentes tienen la obligación y la responsabilidad de prestar asistencia a los desplazados internos que hayan regresado o se hayan reasentado en otra parte, para la recuperación, en la medida de lo posible, de las propiedades o posesiones que abandonaron o de las que fueron desposeídos cuando se desplazaron. Si esa recuperación es imposible, las autoridades competentes concederán a esas personas una indemnización adecuada u otra forma de reparación justa o les prestarán asistencia para que la obtengan.

UNIVERSIDAD VERACRUZANA.

Instituto de Investigaciones Jurídicas

http:// universosjuridicos.uv.mx/index.php/univerjuridicos/index

Xalapa, Veracruz, México 


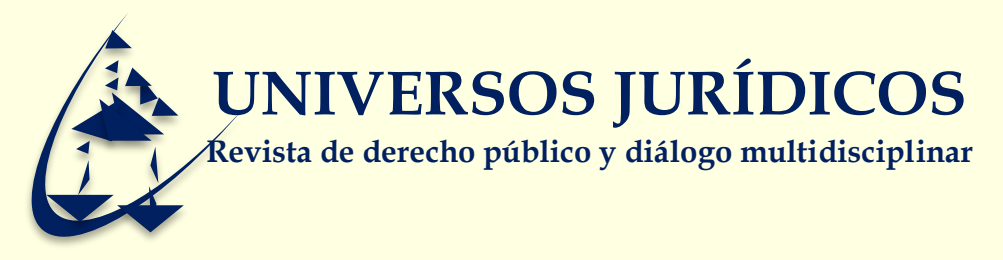

Tristemente el resarcimiento del daño pocas veces ocurre por diversas razones, como la inexistencia de un recurso interno efectivo para solventar las violaciones a los $\mathrm{DDHH}$ de las personas que sufren de desplazamiento interno forzado, aunado al temor de repetir la situación debido a la continua inseguridad, etc., lo que ocasiona que más de la mitad de la población violentada continúe siendo afectada, lo cual se representa en el Grafico 4.

Gráfico 4.- Situación de la población internamente desplazada por la fuerza

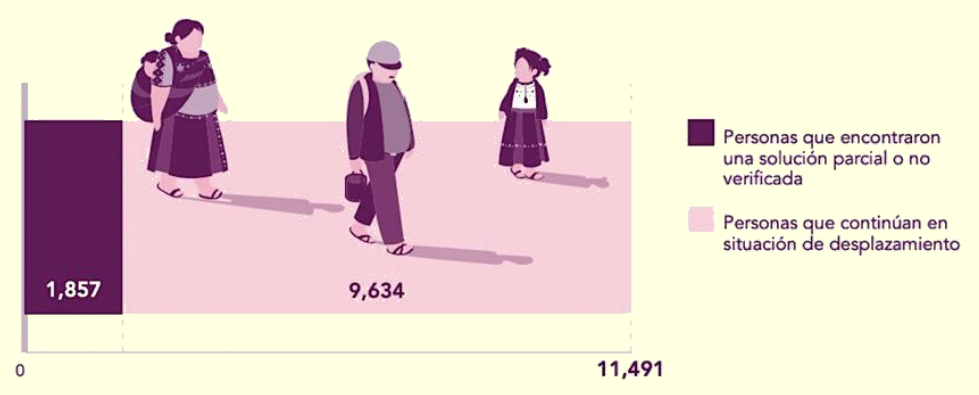

Comisión Mexicana de Defensa y Promoción de los Derechos Humanos A.C., mayo 2019, p.p. 44.

Así mismo el Estado tienen la "obligación específica de tomar medidas de protección contra los desplazamientos de pueblos indígenas, minorías, campesinos, pastores y otros grupos que tienen una dependencia especial de su tierra o un apego particular a la misma (Comunidad G Vs. Surinam, 2005, pág.

UNIVERSIDAD VERACRUZANA.

Instituto de Investigaciones Jurídicas

http://universosjuridicos.uv.mx/index.php/univerjuridicos/index

Xalapa, Veracruz, México 


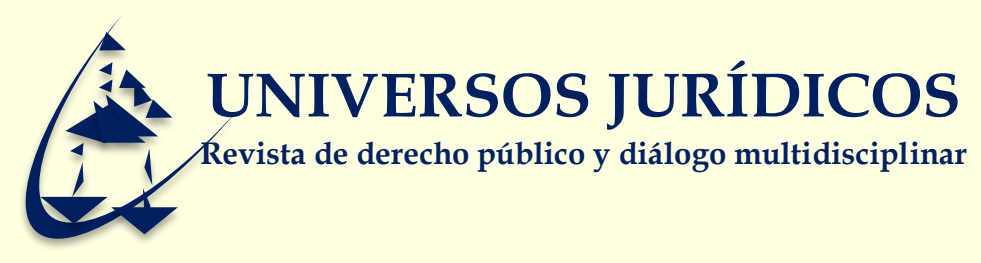

111)", y en éste sentido se busca erradicar las soluciones parciales para lograr soluciones permanentes que beneficien a todas las personas desplazadas forzosamente, otorgándoles la garantía de no repetición, mediante el uso máximo de los recursos disponibles por parte del Estado para menguar la raíz del problema.

De acuerdo con el Marco de Soluciones Duraderas para los Desplazados Internos presentado ante el Consejo de Derechos Humanos de las Naciones Unidas:

\begin{abstract}
Una solución duradera se logra cuando los desplazados internos dejan de necesitar asistencia o protección específicas vinculadas con su situación de desplazamiento y pueden disfrutar de sus derechos humanos sin ser discriminados por esa condición. Para identificar si determinada situación puede ser clasificada como una solución duradera, dicho Marco establece que se deben observar, como mínimo, los siguientes criterios: seguridad y libertad de circulación; un nivel de vida adecuado, incluyendo el acceso a una alimentación adecuada, agua, vivienda, servicios de salud y educación básica; acceso al empleo y a medios de subsistencia; acceso a mecanismos eficaces para la restitución de viviendas, tierras y bienes, o el ofrecimiento de una indemnización; acceso y reemplazo de documentación; reunificación familiar voluntaria; participación integral en los asuntos públicos, en condiciones de igualdad; y recursos efectivos en caso de violación de derechos, como acceso a la justicia, reparación e información.
\end{abstract}

Contexto que no serviría de nada si el estado no garantiza la permanencia en tierras donde re hagan su vida las personas desplazadas, asegurando que no serán desplazados nuevamente, dicha situación de facto de podría solucionar si se les otorgaran títulos de propiedad las comunidades afectadas para tener certidumbre jurídica, pero lo cierto es que para la delincuencia poco importa un título de propiedad, además en el caso de necesitar nuevos asentamientos para poder

\title{
UNIVERSIDAD VERACRUZANA.
}

Instituto de Investigaciones Jurídicas

http://universosjuridicos.uv.mx/index.php/univerjuridicos/index

Xalapa, Veracruz, México 


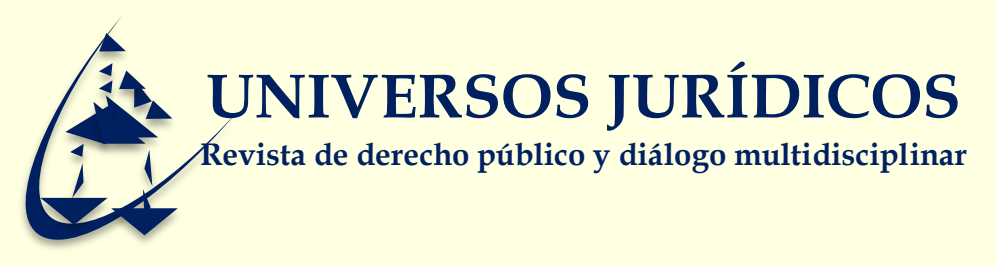

otorgarlos a las comunidades se imposibilita aún más debido a que actualmente ya no quedan latifundios ni extensiones de tierras que repartir debido al crecimiento de la mancha urbana que ha avanzado velozmente suprimiendo cada vez más los pueblos originarios.

De ahí que después del desplazamiento, las víctimas sufren de violaciones múltiples a sus derechos humanos debido a que:

\begin{abstract}
El retorno de los desplazados a sus hogares carece, en muchos casos, de las condiciones necesarias de seguridad y de dignidad para ellos y, dentro de los efectos nocivos de los reasentamientos que provoca el desplazamiento forzado interno, además de graves repercusiones psicológicas en ellos, se han destacado (i) la pérdida de la tierra y de la vivienda, (ii) la marginación, (iii) la pérdida del hogar, (iv) el desempleo, (v) el deterioro de las condiciones de vida, (vi) el incremento de las enfermedades y de la mortalidad, (vii) la pérdida del acceso a la propiedad entre comuneros, (viii) la inseguridad alimentaria, y (ix) la desarticulación social, así como el empobrecimiento y el deterioro acelerado de las condiciones de vida (Masacre de Mapiripán Vs. Colombia, 2005, pág. 175).
\end{abstract}

Bajo éste contexto se encuentra la importancia de garantizar un retorno seguro y digno de las familias a sus hogares o casas de acogida, siempre respetando el principio básico universal de protección a la familia a mantenerlos juntos durante el proceso de resarcimiento del daño porque tal y como consta en el artículo 10 del Pacto Internacional de Derechos Económicos, Sociales y Culturales "la familia, es el elemento natural y fundamental de la sociedad, merecedora de la más amplia protección y asistencia posibles".

UNIVERSIDAD VERACRUZANA.

Instituto de Investigaciones Jurídicas

http://universosjuridicos.uv.mx/index.php/univerjuridicos/index

Xalapa, Veracruz, México 


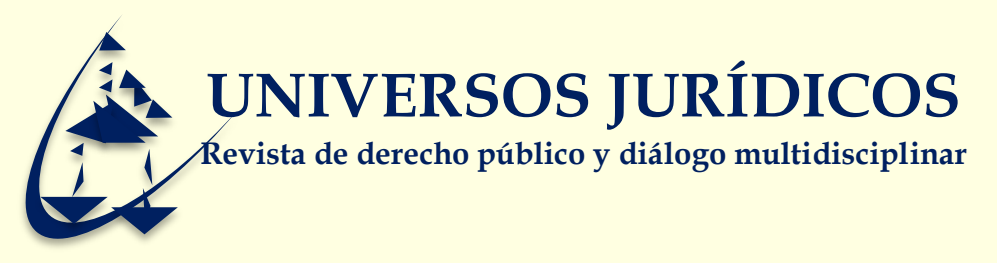

\title{
IV. Los Derechos Humanos violentados frente al desplazamiento interno forzado
}

La En cuanto a la victimización de las personas forzadas a desplazarse internamente significa que:

\begin{abstract}
El Estado no pudo garantizar la protección de estas personas y prevenir su desplazamiento; puede ser de carácter masivo por la cantidad de víctimas que afecta; sistemático porque su ejecución es sostenida en el tiempo y el sistema jurídico y factual es incapaz de atenderlo; así como complejo por la vulneración múltiple y agravada hacia sus derechos civiles y políticos como a sus derechos económicos, sociales y culturales; y es continuo, dado que la condición de vulneración de la población persiste en el tiempo hasta que se logre su retorno asistido, digno y seguro (Pérez, 2019, págs. 112-143).
\end{abstract}

Es por ello que las víctimas de ésta situación sufren una múltiple victimización, primero al abandonar su hogares de manera violenta y forzada, en segundo lugar al ser perjudicadas durante su sinuoso camino por parte de la delincuencia organizada mediante, asaltos, amenazas, violaciones y hasta ser privados de su libertad o de la vida, en tercer lugar al llegar a casas o comunidades de acogida donde son discriminados y segregados bajo la idea equivocada de ser delincuentes, subversivos o que simplemente llevan problemas a la éstos lugares por su origen rural e indígena; pero dicha situación no termina con llegada a una nueva comunidad "segura", debido a que -como ya se mencionó-, para los individuos

UNIVERSIDAD VERACRUZANA.

Instituto de Investigaciones Jurídicas

http://universosjuridicos.uv.mx/index.php/univerjuridicos/index

Xalapa, Veracruz, México 


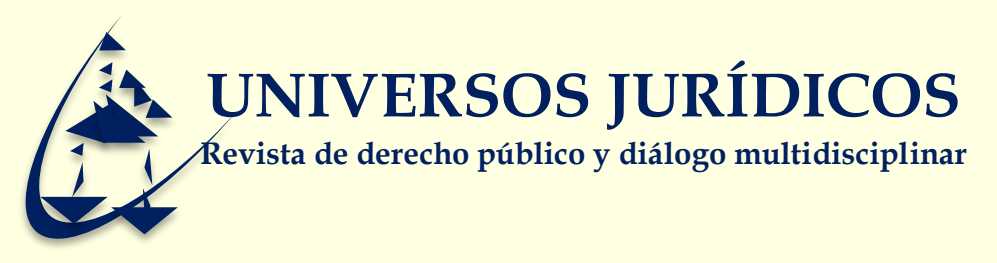

pertenecientes a etnias indígenas tienen un fuerte arraigo con sus comunidades y tierras que la conforman, por ello al mantenerse alejados de las mismas sufren daños psicológicos graves y hasta físicos en razón del desarraigamiento forzado, lo que para ellos equivale a perder su identidad.

Ahora bien, en un sentido más técnico los derechos preponderantemente violados a las personas que experimentan el desplazamiento interno forzado en México, de acuerdo a la Convención Americana de Derechos Humanos (en adelante CADH) son:

- Derecho a la vida $\longrightarrow$ artículo 4 de la CADH.

- Derecho a la Integridad personal $\longrightarrow$ artículo 5 de la CADH.

- Derecho a la libertad personal $\longrightarrow$ artículo 7 de la CADH.

Dentro del cual se encuentra el derecho a la Seguridad Personal.

- Derecho a la honra y dignidad $\longrightarrow$ artículo 11 de la CADH.

Dentro del cual se encuentra el 11.2 relativo a la Prohibición de injerencias arbitrarias en la vida privada y el domicilio.

- Protección a la familia $\longrightarrow$ artículo 17 de la CADH.

- Derechos de los niños $\longrightarrow$ artículo 19 de la CADH.

- Derecho a la propiedad privada $\longrightarrow$ artículo 21 de la CADH. 


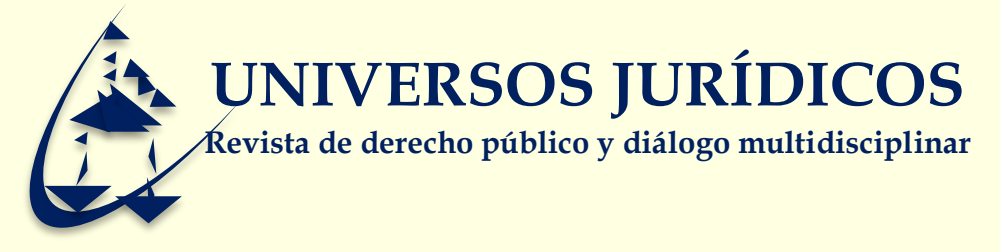

- Derecho de circulación y de residencia $\longrightarrow$ artículo 22 de la CADH.

- Garantías judiciales $\longrightarrow$ artículo 8 de la CADH.

Dentro del cual se encuentra el derecho a un debido proceso.

- Protección judicial $\longrightarrow$ artículo 25 de la CADH.

Dentro del cual se encuentra el derecho a un recurso efectivo.

Como se puede observar en la descripción anterior no es un problema simple, el cual tenga una única manera de solucionarse, al contrario, debe ser abordado integralmente por parte del Estado, con la ayuda la sociedad civil, debido a que es un problema que en palabras simples ha rebasado al mismo Estado.

Al respecto, para poder llegar a comprender adecuadamente como se debe abordar el problema de raíz en necesario hacer un estudio de derecho comparado de México con otras naciones que experimentan el mismo problema, en este caso el más parecido social y geográficamente es Colombia quienes a raíz de las guerrillas colombianas empezadas bajo el dominio del capo de la droga Pablo Escobar, las comunidades indígenas y rurales de ese país estuvieron en una situación aún más precaria y violenta que la que se vive en México. Bajo éste contexto Colombia fue sentenciada varias veces por la Corte Interamericana de Derecho Humanos y a 


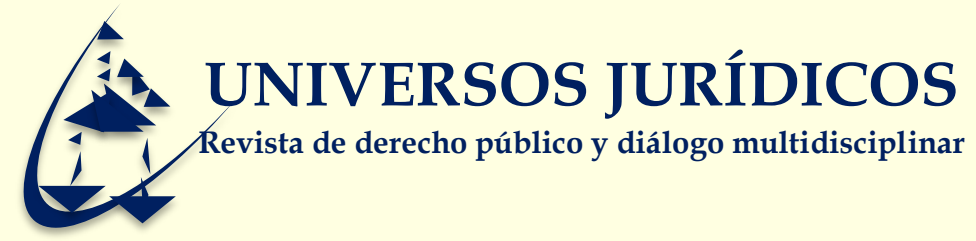

causa de ello creó "La defensoría del pueblo Colombiano" 3 para atender a todas las

personas mediante:

La Ley 387 de 1997, que brinda asesoría a la población en situación de desplazamiento, junto con la Procuraduría General de la Nación y las personerías municipales, la Defensoría del Pueblo hace parte de lo que se denomina el Ministerio Público, y se constituye, como ya se señaló, en la entidad rectora de la defensa, promoción, protección y divulgación de los derechos humanos (Colombia, 2019).

Hecha esta salvedad, con respecto a los derechos violentados a las personas

forzadas a desplazarse internamente, en la legislación internacional se ha pronunciado respeto del derecho a la vida

El cual garantiza no solo el derecho de todo ser humano a no ser privado de la vida arbitrariamente, sino, además, el deber del Estado de adoptar medidas necesarias para crear un marco normativo que disuada cualquier amenaza a éste derecho, así como establecer un sistema de justicia efectivo capaz de investigar, castigar y reparar toda privación de la vida por parte de agentes estatales 0 particulares (Ximenes Lópes Vs. Brasil, 2006, pág. 125).

En éste sentido no se debe dejar de lado la unidad que conforma el derecho a la integridad personal, mismo que prohíbe todo tipo de torturas y penas o tratos crueles e inhumanos en el aspecto del desplazamiento interno forzado ya que si

\footnotetext{
${ }^{3}$ La finalidad del ente Defensorial es la protección de los derechos humanos y de las libertades de todas las personas frente a actos, amenazas o acciones ilegales, injustas, irrazonables, negligentes o arbitrarias de cualquier autoridad o de los particulares. La Defensoría del Pueblo se instituye, entonces, como el organismo tutelar de los derechos y garantías de los habitantes del territorio nacional como de los colombianos residentes en el exterior. Fecha de consulta 26 de enero de 2019, disponible en: http://www.defensoria.gov.co/es/public/institucional/5847/\%C2\%BFQu\%C3\%ADenessomos.htm
}

UNIVERSIDAD VERACRUZANA. Instituto de Investigaciones Jurídicas http://universosjuridicos.uv.mx/index.php/univerjuridicos/index Xalapa, Veracruz, México 


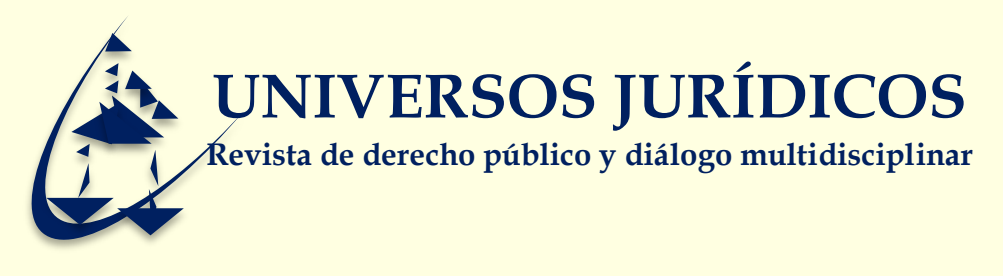

bien muchas personas perecen en el camino a encontrar un nuevo hogar, las que sobreviven también encuentran violentado éstos derechos debido al incumplimiento del estado en garantizarles las medidas necesarias de seguridad para vivir dentro o fuera de su comunidad, a razón de la violencia generalizada que se desarrolla en sus estados de origen, vulnerando además su seguridad personal y su integridad física y psicológica, situación que debería "obligar a los Estados a otorgar un trato preferente a su favor y a adoptar medidas de carácter positivo para revertir los efectos de su referida condición de debilidad, vulnerabilidad e indefensión (Masacre de Mapiripán Vs. Colombia, 2005, pág. 163)", sin embargo es una situación que no sucede debido a que en pro de la buena apariencia internacional que el Estado Mexicano desea transmitir no ha aceptado el deslazamiento interno forzado como un problema real y con ello se niega a llevar a cabo acciones para prevenir o solucionar el problema, lo cual afecta la libertad personal al no garantizar seguridad personal ni jurídica a las personas afectadas.

Por otro lado, las víctimas también se duelen de la violación a sus derechos de protección a la honra y dignidad en el sentido de todos tratos crueles que reciben desde el momento del inicio del desplazamiento hasta que dicho problema termina -situación casi imposible-, lo cual trae aparejado "la destrucción del ganado, los 


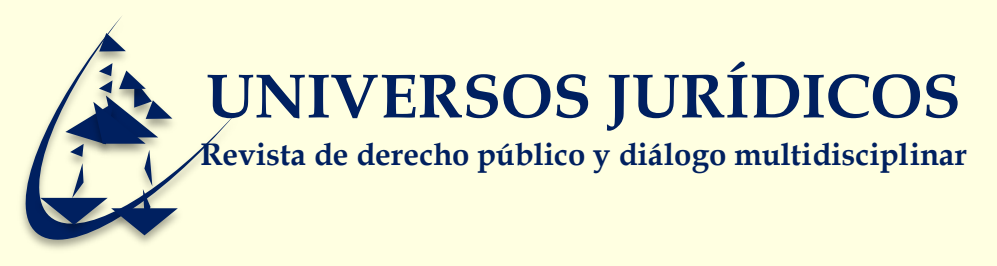

cultivos y las viviendas, en violación del derecho a la propiedad privada, y las injerencias arbitrarias o abusivas en la vida privada y el domicilio (Masacre de El Mezote y Lugares Aledaños Vs. El Salvador, 2012, pág. 195)", debido a que como ya se explicó anteriormente, la delincuencia organizada o el Ejercito mexicano entra a las comunidades por la fuerza y de forma agresiva destruyendo las propiedades para hacer sembradíos de droga o aprovechan los recursos naturales dentro de las mismas para su propio beneficio dejando a los pueblos sin sustento para hacer frente al despojo al que son sometidos. De esta manera y durante las movilizaciones se ven afectadas las familias que si bien por la premura del desplazamiento muchas veces se dividen al intentar huir o bien durante el trayecto se van quedando atrás personas pertenecientes a grupos vulnerables como adultos mayores, niños o mujeres embarazadas, en particular:

Estado tiene el deber de prestar especial atención a las necesidades y a los derechos de los niños, en consideración a su condición particular de vulnerabilidad debido a que han sido especialmente afectados por los desplazamientos familiares, de manera que el Estado violó el derecho a la protección especial por su condición de niños y niñas (Familia Barrios Vs. Venezuela, 2011, pág. 168).

Situación que se muestra en el siguiente Gráfico 5:

UNIVERSIDAD VERACRUZANA.

Instituto de Investigaciones Jurídicas

http://universosjuridicos.uv.mx/index.php/univerjuridicos/index

Xalapa, Veracruz, México 

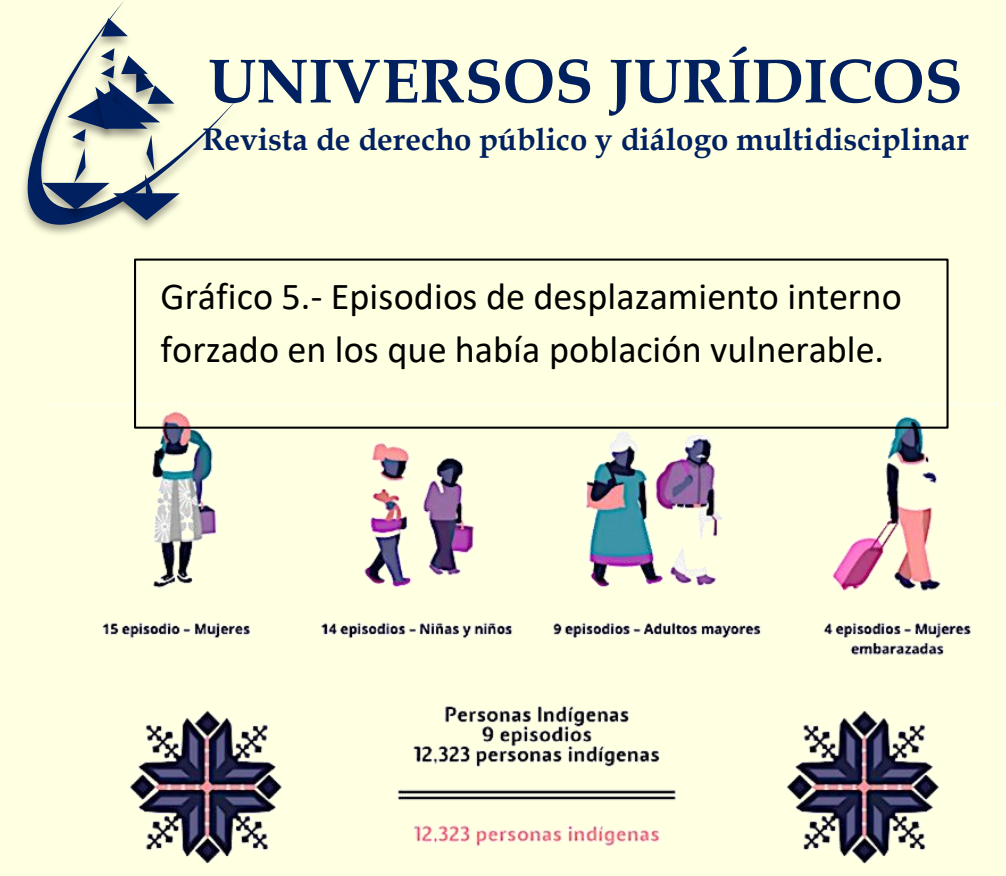

Comisión Mexicana de Defensa y Promoción de los Derechos Humanos A.C., México, 2018.

De igual modo, no existe ningún recurso efectivo al cual las personas individual o colectivamente puedan acudir dentro del sistema jurídico mexicano, debido a que como ya se mencionó el Estado mexicano no lo reconoce como un problema real, en consecuencia no es posible recurrir a ninguna instancia capaz de solucionar dicho conflicto y brindar las medidas adecuadas a las víctimas ante una situación de emergencia; de ahí que el Estado se encuentra violentando además los artículos 8 y 25 de la CADH al no contar con instancias a las cuales acudir antes, durante, ni después del desplazamiento, negándoles así un debido proceso y "obligados a permanecer y a la espera de la resolución de su solicitud de reivindicación de tierras (Comunidad Indígena Yakye Axa Vs. Paraguay, 2005, pág. 164)” en el derecho doméstico, siendo extremadamente dilatorio, como una simple formalidad que de 


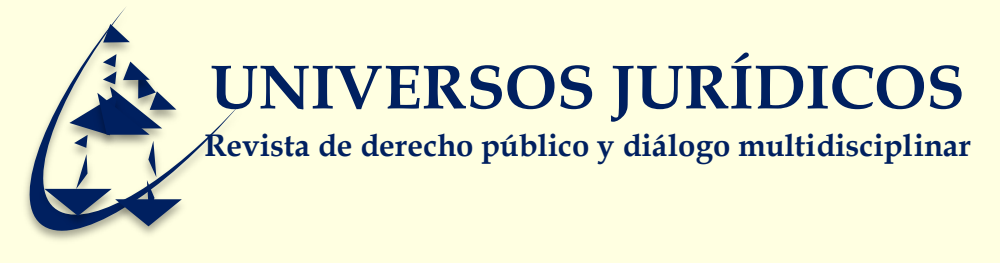

ante mano será infructuosa, además como "consecuencias de las faltas al deber de investigar los hechos, que han derivado en impunidad parcial (Masacre de Mapiripán Vs. Colombia, 2005, pág. 186)" tanto de las autoridades que dentro del ámbito de sus atribuciones no realizan ninguna acción en favor de las víctimas como del crimen organizado, que si bien son perseguidos por delitos contra la salud o por ataques a cuerpos militares, nunca son consignados por el daño ocasionado a éstas indefensas comunidades. Mientras tanto la Corte Interamericana de Derechos Humanos ha realizado una:

Interpretación evolutiva del artículo 22 de la Convención, tomando en cuenta las normas de interpretación aplicables y de conformidad con el artículo 29.b de la Convención que prohíbe una interpretación restrictiva de los derechos, esta Corte considera que el artículo 22.1 de la Convención protege el derecho a no ser desplazado forzadamente dentro de un Estado Parte en la misma, así como derecho constitucional a escoger su lugar de domicilio. (Masacre de Mapiripán Vs. Colombia, 2005, pág. 188)".

Al mismo tiempo al no tener un domicilio fijo no pueden acceder a servicios básicos como agua potable y drenaje, violentando su derecho a la salud de manera indirecta, mismos derechos se han considerado como una "condición indispensable para el libre desarrollo de la persona (Masacre de Santo Domingo Vs. Colombia, 2012, pág. 255)”.

UNIVERSIDAD VERACRUZANA. Instituto de Investigaciones Jurídicas http:// universosjuridicos.uv.mx/index.php/univerjuridicos/index Xalapa, Veracruz, México 


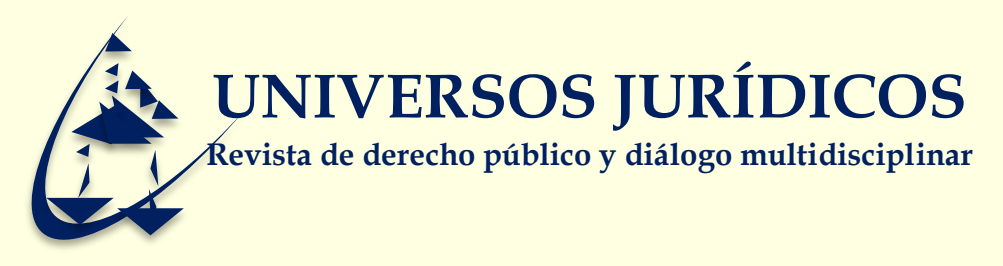

\section{Ausencia de una legislación jurídico-reguladora a nivel federal sobre el desplazamiento interno forzado}

Ante el acelerado crecimiento del problema, se deben tomar acciones inmediatas para comenzar a resolverlo, debido a que a nivel federal no se cuenta con recursos jurídicos ni materiales para realizar dicha acción, contraviene el artículo $1^{\text {o }}$ constitucional el cual estipula que todas las personas deben contar con todos los derechos enmarcados en la constitución, así como los subsecuentes artículo 14 Constitucional que estipula que "nadie podrá ser privado sus propiedades, posesiones o derechos", por otra parte el artículo 16 de la misma Carta Magna establece que "Nadie puede ser molestado en su persona, familia, domicilio, papeles o posesiones", dentro de los cuales además se relacionan con las garantías judiciales del articulo 8 y la protección judicial del artículo 25, ambos de la $\mathrm{CADH}$, todo lo anterior a nivel federal.

Es por ello que al estar viviendo en un régimen falto de observancia de DDHH en la materia de desplazamiento interno forzado es necesario abordar el problema antes de que se convierta en una crisis humanitaria mayor o igual a la que se ha vivido en Colombia desde hace ya varios años. En éste sentido y a falta de un marco normativo vigente "existe un vacío de responsabilidades, así como un vacío 


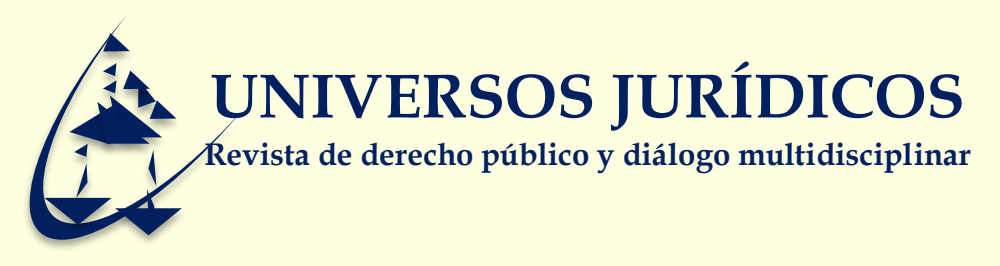

conceptual en torno a la definición del fenómeno, lo que dificulta el reconocimiento del mismo, así como de sus víctimas (Comisión Mexicana de Defensa y Promoción de los Derchos Humanos, 2018)", debido al desconocimiento de estas víctimas ya qué es un problema que aqueja a determinadas zonas del país entre las principales se encuentran los estados de Guerrero y Chiapas, a razón de ello son los únicos dos estados del país que se han preocupado por implementar leyes especializadas en la materia. Dentro de la Ley para la Prevención y Atención del Desplazamiento Interno en el Estado de Chiapas se puede destacar la especial protección que busca brindar a los desplazados, sin embargo la ley utiliza términos como "programas", "autoridades competentes", "medidas especiales", etc., que no son descritos dentro del texto, así mismo no cuenta con una reglamentación en la cual consten los medios y formas de hacer efectiva dicha legislación es por ello que a pesar de contar con los derechos a proteger no hay ningún medio de garantía para hacerlos valer. Así mismo existen diversas legislaciones no especializadas en donde se abordan a las personas internamente desplazadas como un grupo vulnerable, dentro de ellas podemos encontrar las principales dentro de la tabla 1. 


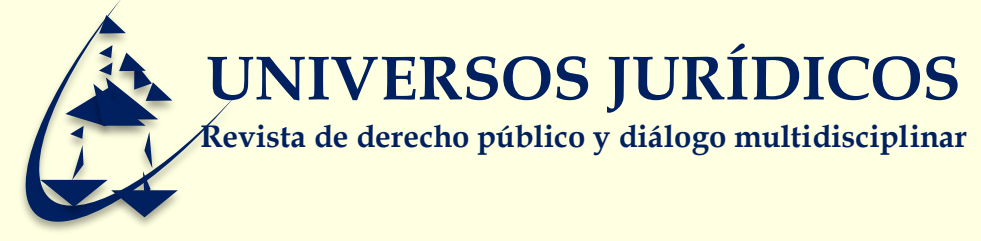

Tabla 1- Legislaciones estatales que contemplan a los Desplazados internos como víctimas.

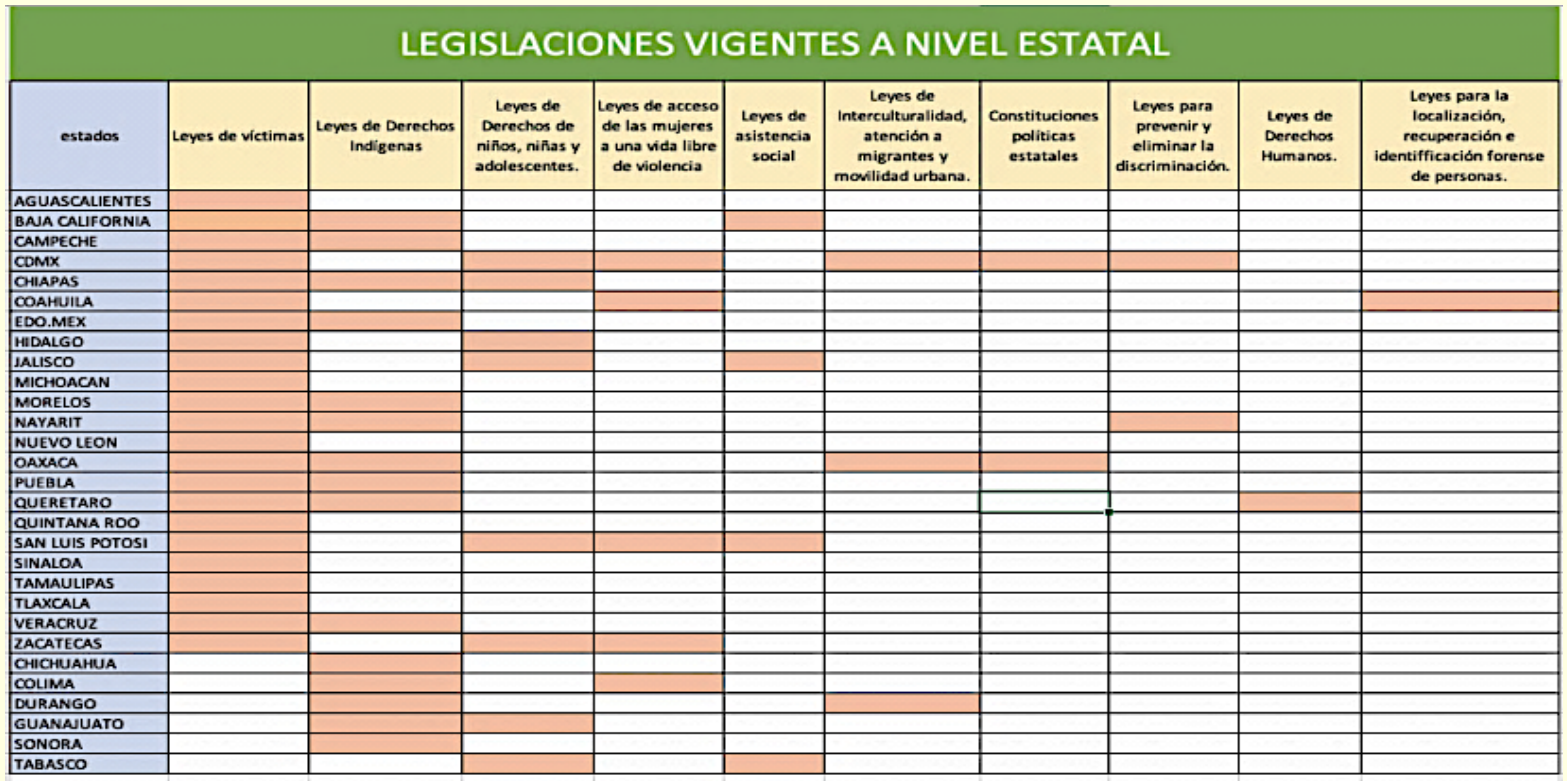

Elaboración propia, con fuente en lo planteado por comisión Mexicana de Defensa y Promoción de los Derechos Humanos A.C., Desplazamiento Interno Forzado en Méxic fecha de consulta 25 de junio de 2019, disponible en: http://cmdpdh.org/temas/desplazamiento/marco-normativo

Mientras que, por otro lado, a nivel federal únicamente dos legislaciones

\section{contemplan dichos casos especiales, la Ley General de Víctimas que:}

incluye a las víctimas de desplazamiento interno forzado en diversos artículos, especialmente en aquellos que se refieren a los grupos expuestos a un mayor riesgo de violación de sus derechos y que requieren atención con enfoque diferencial y especializado. Asimismo, determina que la Comisión Ejecutiva y las Comisiones Ejecutivas de las entidades federativas garantizarán, cuando proceda, el derecho de las víctimas de desplazamiento interno que se encuentren fuera de su entidad de origen a su registro, atención y reparación. Sin embargo, esta ley omite la inclusión de una definición del desplazamiento interno forzado, lo que representa un vacío conceptual importante y genera obstáculos para el reconocimiento y atención de las víctimas (Comisión Mexicana de Defensa y Promoción de los Derchos Humanos, 2018).

UNIVERSIDAD VERACRUZANA.

Instituto de Investigaciones Jurídicas

http://universosjuridicos.uv.mx/index.php/univerjuridicos/index

Xalapa, Veracruz, México 


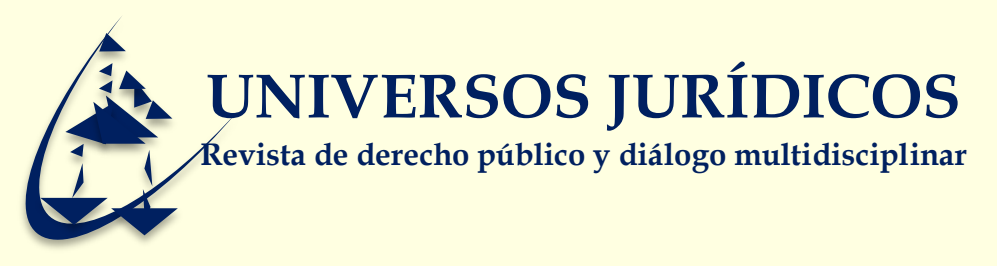

Y la Ley de Asistencia Social, la cual:

\begin{abstract}
Determina que tienen derecho a la asistencia social "los individuos y familias que, por sus condiciones físicas, mentales, jurídicas, económicas o sociales, requieran de servicios especializados para su protección y su plena integración al bienestar". Dicha ley incluye, de manera específica, a los "indígenas desplazados" entre los grupos que son sujetos preferentes de la asistencia social, y que deben recibir servicios de representación y asistencia jurídica, así como de orientación social, del Sistema Nacional para el Desarrollo integral de la familia (DIF).
\end{abstract}

La poca legislación actual vigente y especializada con que se cuenta no quiere decir que no sea un problema menor, sino, que es un problema que la población nacional elige no observar, sin embargo ello no evita que los defensores de derechos humanos junto con los estados más afectados por éste fenómeno promuevan acciones que sirvan como paliativos a la problemática, así como también buscan que se regularice la situación mediante diversos métodos legislativos como iniciativas le leyes, iniciativas de reformas constitucionales, hasta solicitudes para reformar el Código Penal Federal y así establecer el desplazamiento interno forzado como un delito federal merecedor de más atención legislativa y su respectiva reglamentación acorde a los estándares internacionales de DDHH, prueba de ello consta en el siguiente Gráfico 6.

UNIVERSIDAD VERACRUZANA. Instituto de Investigaciones Jurídicas http:/ / universosjuridicos.uv.mx/index.php/univerjuridicos/index Xalapa, Veracruz, México 


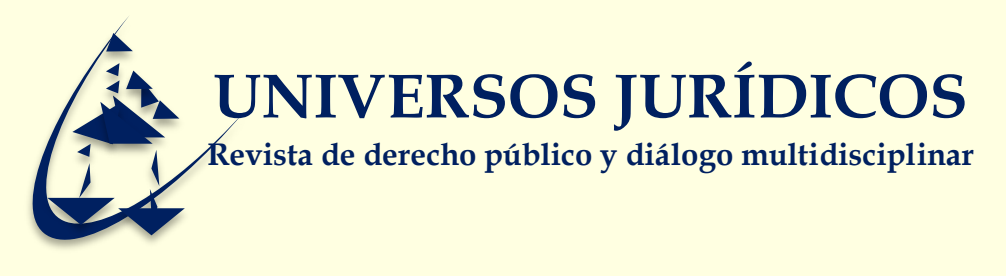

Gráfico 6.- Iniciativas de propuestas legislativas a nivel federal para reconocer el Desplazamiento Interno Forzado.

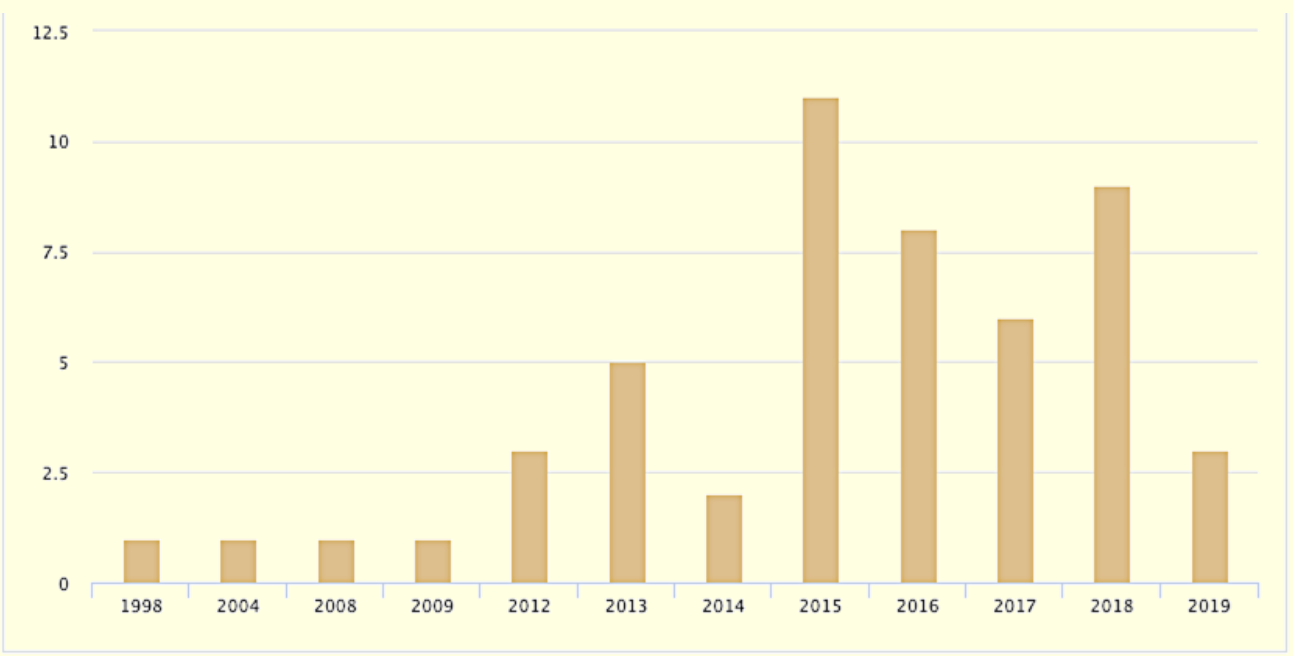

Comisión Mexicana de Defensa y Promoción de los Derechos Humanos A.C., Desplazamiento Interno Forzado en México: Marco normativo, fecha de consulta 25 de junio de 2019, disponible en: http://cmdpdh.org/temas/desplazamiento/marco-normativo

Dentro de las iniciativas del año 2019 podemos destacar La Ley General Sobre Desplazamiento Forzado Interno, en la cual dentro de la exposición inicial de motivos explica la diferenciación que se debe hacer de éste fenómeno en contraste con la migración, así como las causas preponderantes por las cuales se da el desplazamiento, aunado a las formas de combatirlo y prevenirlo, no sin dejar de lado que en el Plan Nacional actual busca dar prioridad a los pueblos originarios así como a las regiones rurales del país por medio de la otorgación de mayores

UNIVERSIDAD VERACRUZANA. Instituto de Investigaciones Jurídicas http://universosjuridicos.uv.mx/index.php/univerjuridicos/index Xalapa, Veracruz, México 


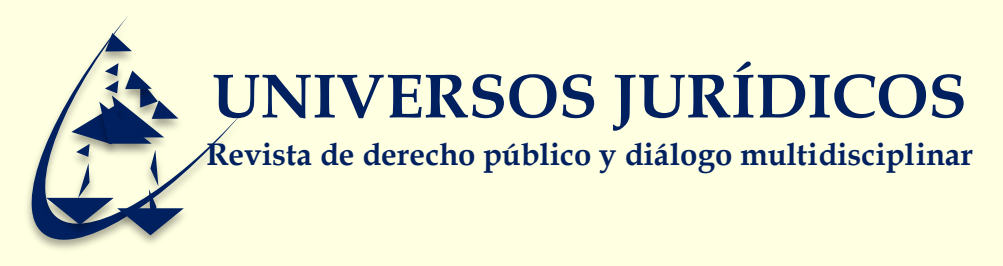

recursos públicos y con ello significaría tener las herramientas necesarias para combatir esta problemática.

\section{Conclusión}

Como ya se explicó en el punto inmediato anterior, en el Estado Mexicano no cuenta con una regulación a nivel federal en el tema de desplazamiento interno forzado, únicamente existen dos leyes estatales en Guerrero y Chiapas, mismas que al no tener un reglamento que asegure las bases para su aplicación y asignación de recursos federales, únicamente quedan como simples recomendaciones o directrices, ya que no existe un medio efectivo para exigir su cumplimiento; en este sentido podemos destacar también la ausencia de instituciones y programas oficiales que poyen y resuelvan dicho tema, por cuanto hace a la Ley General de Víctimas a falta de otro instrumento vinculatorio, es el medio legal, vigente y adecuado para ejercer los derechos de las personas víctimas de desplazamiento interno forzado, siendo que al mismo tiempo es insuficiente; ya que si bien es cierto que a diferencia de cualquier otra ley federal contempla por primera vez a los desplazados internos como víctimas al mencionarlos en su artículo 5 inciso V, el cual a la letra dice: 


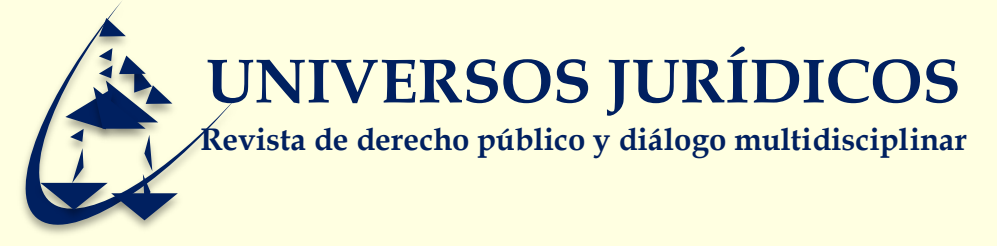

\begin{abstract}
Las autoridades que deban aplicar esta Ley ofrecerán, en el ámbito de sus respectivas competencias, garantías especiales y medidas de protección a los grupos expuestos a un mayor riesgo de violación de sus derechos, como niñas y niños, jóvenes, mujeres, adultos mayores, personas en situación de discapacidad, migrantes, miembros de pueblos indígenas, personas defensoras de derechos humanos, periodistas y personas en situación de desplazamiento interno. En todo momento se reconocerá el interés superior del menor.
\end{abstract}

Esta ley asegura que el enfoque dado a las víctimas que pertenezca a grupos vulnerables sea de manera integral y transversal atendiendo a los estándares internacionales de los $\mathrm{DDHH}$, proporcionando en todo momento acompañamiento y atención médica y psicológica a las víctimas que necesiten una especial atención, en este sentido es un gran avance para la legislación mexicana, aunque en todos los casos la mejor arma es la prevención, cuestión que falta aún regular.

Ahora bien, la falta de regulación de la situación que nos ataña es debido a que el Estado no reconoce el desplazamiento interno forzado como un problema real y latente, tal y como deja claro en "el escrito de información remitida por la [Unidad de Derechos Humanos de la Secretaria de Gobernación] UDDH-SEGOB se realiza un análisis sobre la definición de las causas del DFI, según los Principios Rectores, para concluir que en México

No se acredita la existencia de ninguno de los elementos necesarios para la presencia de un desplazamiento forzado interno, por lo que no es posible su reconocimiento, agregando que, si bien existe movilidad por causa de la violencia, ésta no es de carácter generalizado (Pérez, 2019, págs. 112-143).

UNIVERSIDAD VERACRUZANA.

Instituto de Investigaciones Jurídicas

http://universosjuridicos.uv.mx/index.php/univerjuridicos/index

Xalapa, Veracruz, México 


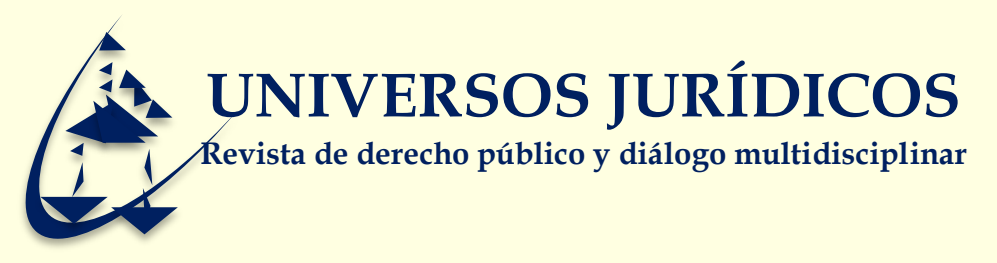

Es a razón de esta negativa de reconocer el problema y la falta de disposición para erradicarlo que la sociedad de ha visto en la necesidad de formar grupos que si bien no pueden atender integralmente el problema, llevan a cabo acciones de cuantificación para lograr que el gobierno federal lo reconozca como un problema real, digno de atención y destinación de recursos para prevenirlos y solucionarlo.

En contraste, el único proyecto llevado a cabo a nivel federal para la atención de emergencias relacionadas con indígenas víctimas de desplazamiento interno forzado estuvo vigente desde 2006 hasta 2015, "operado por la Comisión Nacional para el Desarrollo de los Pueblos Indígenas (CDI), actualmente Instituto Nacional de los Pueblos Indígenas (INPI), fue desactivado debido a una reestructuración programática, presupuestal y operativa (Comisión Mexicana de Defensa y Promoción de los Derchos Humanos, 2018)", mismo que desde esa fecha no ha vuelto a ponerse en marcha, prueba clara del desinterés de los operadores legislativos sobre el tema dejando nuevamente a las víctimas en una desprotección de facto, ya que:

Mientras estuvo activo, el proyecto atendió a 6,678 familias indígenas en los estados de Chiapas, Guerrero, Hidalgo, Guanajuato, Nayarit, Oaxaca y Jalisco. Los apoyos brindados por el proyecto consistían en la adquisición de tierras de cultivo, solares urbanos, materiales para la construcción de viviendas, insumos para actividades productivas y letrinas ecológicas, así como apoyo para la

UNIVERSIDAD VERACRUZANA.

Instituto de Investigaciones Jurídicas

http://universosjuridicos.uv.mx/index.php/univerjuridicos/index

Xalapa, Veracruz, México 


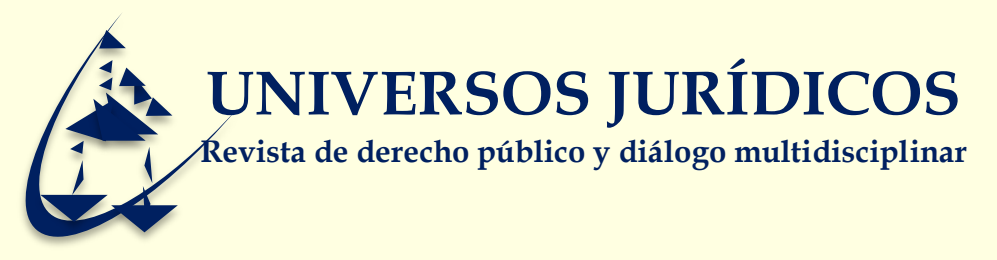

recuperación de propiedades y gestiones para la escrituración de terrenos (Comisión Mexicana de Defensa y Promoción de los Derchos Humanos, 2018).

Por consiguiente, es urgente que el Estado comience a actuar en favor de las personas en la situación de vulnerabilidad, que el mismo Estado por sus omisiones las ha generado y así lleguen formalizarse en programas activos y efectivos que no sean cancelados por falta de recurso. En consecuencia, los indígenas forzados a desplazarse internamente, sufren una triple discriminación, primeramente al vivir en sus comunidades son segregados y discriminados por su origen étnico, faltos de recursos económicos tanto federales como locales para preservar sus tierras y tener una vida digna, incurriendo el Estado en una omisión legislativa al no otorgar las garantías efectivas para que prevalezca su derecho a la vida y a la integridad; en una segunda cuestión, sufren desplazamiento interno forzado como "daño colateral" de la delincuencia organizada y los enfrentamientos que tienen con el Ejercito Mexicano, violentando así su derecho a la seguridad personal y en una tercera instancia, al ser desplazados y llegar a comunidades o casas de acogida son calificados de subversivos, delincuentes, personas que solo causan problemas, generando nuevamente segregación por su origen rural, sin justificación alguna, teniendo así el Estado la obligación de resarcir el daño y además procurar que su regreso y travesía sean siempre apegados a los $\mathrm{DDHH}$. Por consiguiente es 


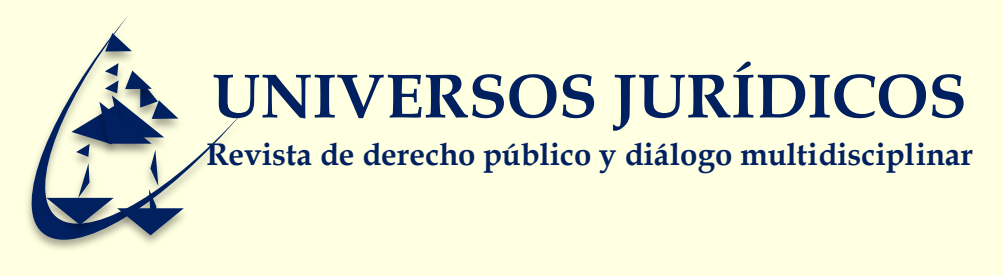

necesario atacar de raíz la problemática identificando adecuadamente las razones que la generaron, a través de éste artículo se han detectado algunas como lo son:

- Inseguridad generalizada.

- Condiciones de extrema pobreza, que lleva a las personas a unirse a grupos de delincuencia organizada, generando el crecimiento de los mismo y así dotándolos de recursos para enfrentarse al Ejercito mexicano o buscar expandir su poder, ocasionando el desplazamiento interno forzado.

- Abuso de poder por parte del Ejercito mexicano al arribar a las comunidades en cuestión y cometer violaciones en contra de los miembros.

- Impunidad hacia las personas responsables del desplazamiento, lo que permite que continúe existiendo.

Lo que a su vez genera como consecuencia:

- Estigmatización, que sufren las personas internamente desplazadas.

- Violencia física y psicológica, antes, durante y después del desplazamiento.

- Fragmentación y ruptura de las comunidades afectadas.

- Violación a derechos humanos. 


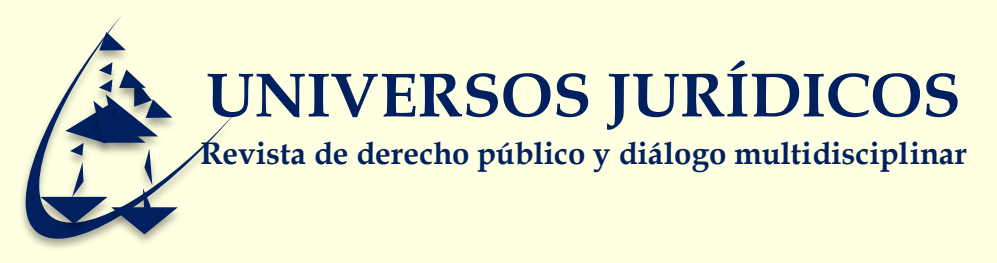

- Al ser un tipo de desplazamiento gota a gota, hace que se desconozca la magnitud del fenómeno.

- El casi imposible seguimiento de las víctimas debido a su temor por ser encontrados por quienes los desplazaron.

- Desarraigo sufrido por indígenas separados de sus tierras ancestrales.

- Temor por represalias por parte de los desplazados al denunciar a sus agresores.

De manera que la única forma de erradicar el problema es que mediante programas sociales federales en vinculación con la ayuda de las entidades municipales para que gestionen la creación de una plan integral y especializado, adecuado a la situación actual, que sea materialmente factible y no quede únicamente como letra pétrea como lo son las legislaciones estatales de Guerrero y Chiapas, en ese contexto se puede tomar como ejemplo las medidas implementadas por Colombia mediante "la creación de mecanismos (registro nacional de desplazados, seguimiento a nivel federal, local y municipal de los mismos, etc.) y el diseño de una estrategia nacional y local de atención (prevención, retorno, asistencia humanitaria, etc. (Aquino, 2008, pág. 77). 


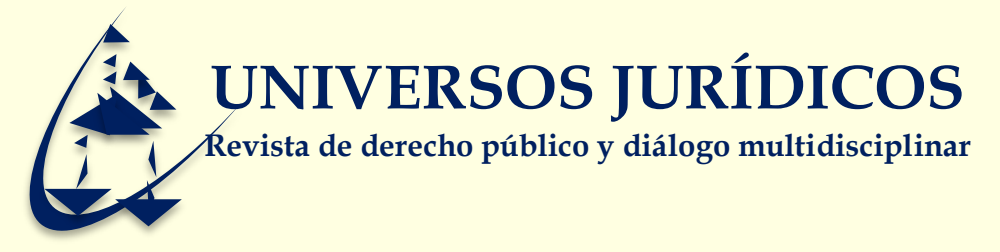

\section{Bibliografía}

Aquino, T. (2008). Hacia la Construcción de Políticas Públicas en Materia de Atención a Grupos Discriminados a Causa del Desplazamiento Forzado de su Lugar de Origen. México: Consejo Nacional para Prevenir la Discriminación (CONAPRED).

Comisión Mexicana de Defensa y Promoción de los Derechos Humanos A.C., Informe 2018: Episodios de desplazmiento interno forzado masivo en México, México, Enero 2019.

Colombia. (26 de enero de 2019). La defensoría del pueblo colombiano . Obtenido de ¿Quiénes somos?: https://www.defensoria.gov.co/es/public/institucional/5847/¿Qu\%C3\%ADenessomos.htm

Comisión Mexicana de Defensa y Promoción de los Derchos Humanos, A. (2018). Informe 2017: Episodios de Desplazamiento Interno Forzado Masivo en México. México.

Comunidad G Vs. Surinam, 111 (Corte Interamericana de Derechos Humanos 15 de junio de 2005).

Comunidad Indígena Yakye Axa Vs. Paraguay, 164 (Corte Interamericana de Derechos Humanos 17 de junio de 2005).

Constitución Política de los Estados Unidos Mexicanos, 2 (5 de Febrero de 1917).

Cruz, J. (2007). Las Condiciones del Desplazamiento Interno en Chiapas. México: UNAM.

Cuevas, J. R. (22 de Diciembre de 2007). La masacre de Acteal, culminación de una política de Estado contra indígenas. La Jornada.

Familia Barrios Vs. Venezuela, 168 (Corte Interamericana de Derechos Humanos 24 de noviembre de 2011).

Masacre de El Mezote y Lugares Aledaños Vs. El Salvador, 194 (Corte Interamericana de Derechos Humanos 25 de octubre de 2012).

Masacre de Ituango Vs. Colombia, 209 (Corte Interamericana de Derechos Humanos 1 de julio de 2006).

\section{UNIVERSIDAD VERACRUZANA.}

Instituto de Investigaciones Jurídicas

http://universosjuridicos.uv.mx/index.php/univerjuridicos/index

Xalapa, Veracruz, México 


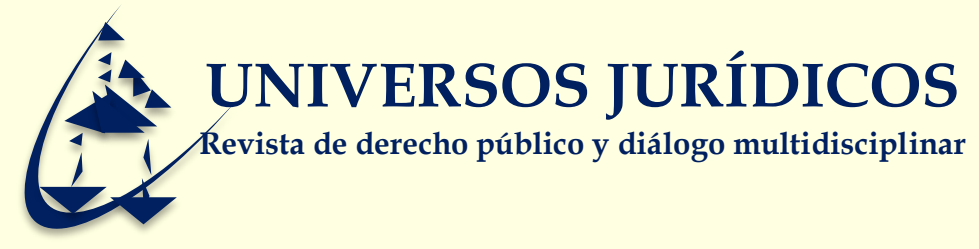

Masacre de Mapiripán Vs. Colombia, 177 (Corte Interamericana de Derechos Humanos 15 de septiembre de 2005).

Masacre de Río Negro Vs. Guatemala, 177 (Corte Interamericana de Derechos Humanos 4 de septiembre de 2012).

Masacre de Santo Domingo Vs. Colombia, 255 (Corte Interamericana de Derchos Humanos 30 de noviembre de 2012).

Mercado, J. (25 de enero de 2019). El Desplazamiento Interno Forzado en México. El Cotidiano, págs. 181-192.

Pérez, B. (2019). Huir de las Violencias: Las Víctimas Ocultas de la Guerra en México, El Caso del Desplazamiento Interno Forzado. Encartes, 112-143.

Rubio, L. (2014). Desplazamiento Interno Inducido por la Violencia: Una Experiencia Global, Una Realidad Mexicana. México : Tres picos.

Ximenes Lópes Vs. Brasil, 125 (Corte Interamericana de Derechos Humanos 4 de julio de 2006).

Zolla, C. (2004). Los Pueblos Indígenas de México, 100 preguntas. México: UNAM.

UNIVERSIDAD VERACRUZANA.

Instituto de Investigaciones Jurídicas

http:// universosjuridicos.uv.mx/index.php/univerjuridicos/index

Xalapa, Veracruz, México 